University of Rhode Island

DigitalCommons@URI

Open Access Master's Theses

2016

\title{
Validation of Bioelectrical Impedance Analysis for the Measurement of Appendicular Lean Mass in Older Women
}

\author{
Kayla Mahoney \\ University of Rhode Island, krounds@my.uri.edu
}

Follow this and additional works at: https://digitalcommons.uri.edu/theses

\section{Recommended Citation}

Mahoney, Kayla, "Validation of Bioelectrical Impedance Analysis for the Measurement of Appendicular Lean Mass in Older Women" (2016). Open Access Master's Theses. Paper 845.

https://digitalcommons.uri.edu/theses/845

This Thesis is brought to you for free and open access by DigitalCommons@URI. It has been accepted for inclusion in Open Access Master's Theses by an authorized administrator of DigitalCommons@URI. For more information, please contact digitalcommons@etal.uri.edu. 
VALIDATION OF BIOELECTRICAL IMPEDANCE ANALYSIS FOR THE MEASUREMENT OF APPENDICULAR LEAN MASS IN OLDER WOMEN

BY

KAYLA MAHONEY

A THESIS SUBMITTED IN PARTIAL FULFILLMENT OF THE

REQUIREMENTS FOR THE DEGREE OF

MASTER OF SCIENCE

IN

KINESIOLOGY

UNIVERSITY OF RHODE ISLAND

2016 


\section{MASTER OF SCIENCE THESIS}

$\mathrm{OF}$

KAYLA MAHONEY

APPROVED:

Thesis Committee:

Major Professor: Matthew Delmonico

Furong Xu

Ingrid Lofgren

Nassir H. Zawia

DEAN OF THE GRADUATE SCHOOL

UNIVERSITY OF RHODE ISLAND

2016 


\begin{abstract}
Segmental multi-frequency bioelectrical impedance analysis (SMF-BIA) has been shown to be a valid, more portable, and less expensive alternative to dual energy X-ray absorptiometry (DXA) for the measurement of appendicular lean mass (ALM) in several populations. However, few studies have examined the validity of SMF-BIA specifically among populations of older women classified as sarcopenic or dynapenic. The aim of this cross sectional study was to investigate the accuracy of SMF-BIA compared to the gold standard DXA for the measurement of ALM among sarcopenic and/or dynapenic older women. Physical function, ALM, strength, and anthropometric tests were performed to determine the presence of sarcopenia and/or dynapenia in a sample of 25 older $(72.3 \pm 4.6$ years $)$ women using established sarcopenia classification criteria. Estimation of ALM using SMF-BIA and DXA were performed under standardized testing conditions. Both techniques were administered within the same hour with participants adequately hydrated, fasted, following urine elimination, and while wearing hospital scrubs. A Pearson correlation coefficient was used to determine a relationship between the two methods for ALM and agreement between the two techniques was assessed using a Bland-Altman plot method. Statistical significance was set at $p<0.05$. A significant and strong correlation was observed between the two techniques with a Pearson's correlation coefficient of 0.88 $(95 \% \mathrm{CI}=0.75$ to $0.95 ; \mathrm{p}<0.001)$. The Bland-Altman plot showed a mean difference of $0.5 \mathrm{~kg}$ and an indication of overall agreement between techniques. However, SMFBIA overestimated ALM for one participant $(-2.9 \mathrm{~kg}, 95 \% \mathrm{CI}=-3.76$ to -2.03$)$ and underestimated ALM for another participant $(1.8 \mathrm{~kg}, 95 \% \mathrm{CI}=0.98$ to 2.71$)$ compared
\end{abstract}


to DXA. The findings indicate overall agreement between SMF-BIA and DXA for the estimation of ALM among older women with characteristics of sarcopenia, but SMFBIA may overestimate or underestimate ALM in some individuals. These data suggest that SMF-BIA may be an acceptable alternative to DXA for the assessment of ALM in older women with characteristics of sarcopenia. 


\section{ACKNOWLEDGEMENTS}

The funding for the URI Resistance Exercise Study to Reclaim Lean Mass and Strength (URI RESTORE ME) was generously provided by the College of Human Science and Services. The study was conducted by the Department of Kinesiology and the Department of Nutrition and Food Sciences. I would first like to extend sincere thanks to all faculty involved with the project including Dr. Delmonico, Dr. $\mathrm{Xu}$, Dr. Hatfield, and Dr. Lofgren. I am thankful to have been offered support and guidance by each of the investigators along the way. I would like to recognize Dr. Delmonico's efforts in particular as my primary advisor for the project. If it were not for his valuable feedback, organization, motivation, and passion for advancing the field of kinesiology, completing a thesis project would not have been possible. I would also like to thank my fellow graduate study coordinators, Sam Slezak and Emily Renna for all of their hard work and dedication through all phases of the study. Finally, I would like to thank my husband Brian for supporting me over the past two years while I struggled to balance school, three jobs, and a social life. The support from all of the above mentioned individuals has ultimately led to successful completion of my thesis in addition to the advancement of knowledge in the field of sarcopenia and body composition research. 


\section{PREFACE}

This thesis is written to comply with the University of Rhode Island graduate school manuscript format. The thesis document contains one manuscript: Validation of Bioelectrical Impedance Analysis for the Measurement of Appendicular Lean Mass in Older Women. The manuscript has been written in a form formatted for publication in the International Journal of Body Composition Research. 


\section{TABLE OF CONTENTS}

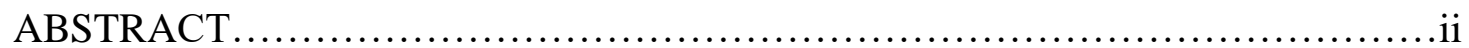

ACKLOWLEDGEMENTS .......................................................

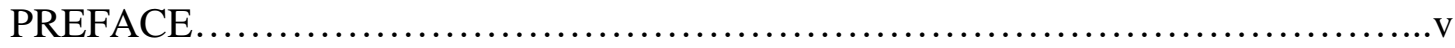

TABLE OF CONTENTS .........................................................vi

LIST OF TABLES...............................................................

LIST OF FIGURES.............................................................

MANUSCRIPT: Validation of Bioelectrical Impedance Analysis for the Measurement of Appendicular Lean Mass in Older Women......................................

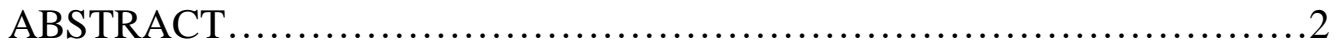

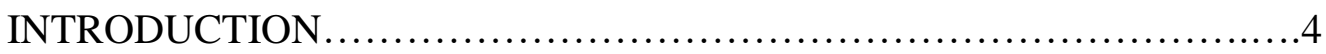

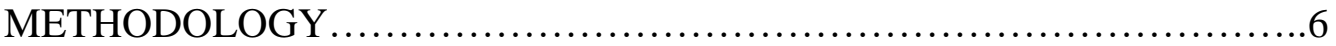

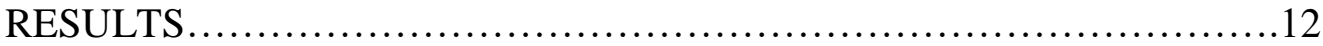

DISCUSSION .............................................................. 14

CONCLUSION .............................................................

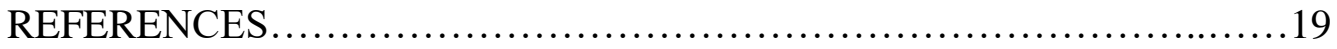

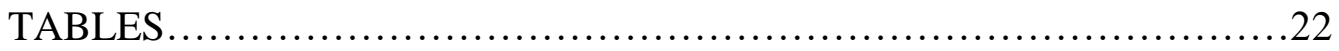

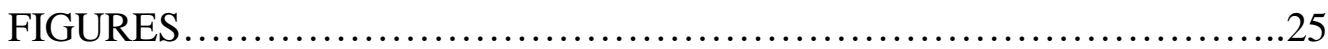




\section{APPENDICES}

APPENDIX A: Review of the Literature ...............................28

APPENDIX B: Phone Screening Assessment.............................46

APPENDIX C: Consent form for Research.............................51

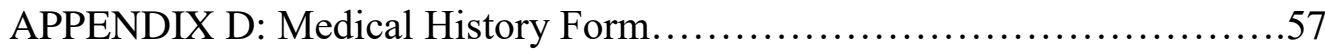

APPENDIX E: Baseline Data Collection Sheet............................63

APPENDIX F: Yale Physical Activity Survey (YPAS) ...................69

APPENDIX G: Dietary Screening Tool (DST) .........................73 


\section{LIST OF TABLES}

Table 1. Baseline Participant Characteristics

Table 2. Fisher's Exact Test for Sarcopenia Classification Based on European Working Group on Sarcopenia in Older People (EWGSOP) Criteria Comparing Segmental Multi-frequency Bioelectrical Impedance (SMF-BIA) and Dual Energy Xray Absportiometry (DXA)

Table 3. Fisher's Exact Test for Sarcopenia Classification Based on the Foundation for the National Institute of Health Sarcopenia Project (FNIHSP) Definition Comparing Segmental Multi-frequency Bioelectrical Impedance (SMF-BIA) and Dual Energy X-ray Absportiometry (DXA) 


\section{LIST OF FIGURES}

Figure 1. Study Flow Chart

Figure 2. Pearson's Correlation Coefficient between Segmental Multi-frequency

Bioelectrical Impedance (SMF-BIA) and Dual Energy X-ray Absorptiometry (DXA) for the Measurement of Appendicular Lean Mass (ALM)

Figure 3. Bland-Altman Plot Comparing Appendicular Lean Mass (ALM) by Segmental Multi-frequency Bioelectrical Impedance (SMF-BIA) and DualEnergy Xray Absorptiometry (DXA) 


\section{MANUSCRIPT}

\section{Validation of Bioelectrical Impedance Analysis for the Measurement of Appendicular Lean Mass in Older Women}

This manuscript was prepared for submission to: The International Journal of Body Composition Research

Manuscript Type: Original Research

Authors: Kayla B. Mahoney ${ }^{\mathrm{a}}$, Sam G. Slezak ${ }^{\mathrm{a}}$, Emily N. Renna ${ }^{\mathrm{a}}$, Furong Xu ${ }^{\mathrm{a}}$, Ingrid E. Lofgren ${ }^{\mathrm{b}}$, Disa L. Hatfield, Matthew J. Delmonico ${ }^{\mathrm{a}}$

${ }^{a}$ Department of Kinesiology, University of Rhode Island, Independence Square II, Kingston, Rhode Island, 02881, USA

${ }^{\mathrm{b}}$ Department of Nutrition and Food Sciences, University of Rhode Island, Ranger

Hall, Kingston, Rhode Island, 02881, USA

Funding support: Funding provided by the College of Human Science and Services at the University of Rhode Island

Conflict of interest: We certify that no party having direct interest in the results of the research that support this article.

Acknowledgements: The authors would like to extend their gratitude to undergraduate research assistants from the Department of Kinesiology, and to all of the participants for their commitment and involvement in the study. 


\begin{abstract}
Objective: Segmental multi-frequency bioelectrical impedance analysis (SMF-BIA) has been shown to be a valid, more portable, and less expensive alternative to dual energy x-ray absorptiometry (DXA) for the measurement of appendicular lean mass (ALM) in several populations. However, few studies have examined the validity of SMF-BIA specifically among populations of older women classified as sarcopenic or dynapenic. The aim of this cross sectional study was to investigate the accuracy of SMF-BIA compared to the gold standard DXA for the measurement of ALM among sarcopenic and/or dynapenic older women.
\end{abstract}

Methods: Physical function, ALM, strength, and anthropometric tests were performed to determine the presence of sarcopenia and/or dynapenia in a sample of 25 older $(72.3$ \pm 4.6 years) women using established sarcopenia classification criteria. Estimation of ALM using SMF-BIA and DXA were performed under standardized testing conditions. Both techniques were administered within the same hour with participants adequately hydrated, fasted, following urine elimination, and while wearing hospital scrubs. A Pearson correlation coefficient was used to determine a relationship between the two methods for ALM and agreement between the two techniques was assessed using a Bland-Altman plot method. Statistical significance was set at $\mathrm{p}<$ 0.05 .

Results: A significant and strong correlation was observed between the two techniques with a Pearson's correlation coefficient of $0.88(95 \% \mathrm{CI}=0.75$ to $0.95 ; \mathrm{p}<$ 0.001). The Bland-Altman plot showed a mean difference of $0.5 \mathrm{~kg}$ and an indication of overall agreement between techniques. However, SMF-BIA overestimated ALM 
for one participant $(-2.9 \mathrm{~kg}, 95 \% \mathrm{CI}=-3.76$ to -2.03$)$ and underestimated ALM for another participant $(1.8 \mathrm{~kg}, 95 \% \mathrm{CI}=0.98$ to 2.71$)$ compared to DXA.

Discussion: The findings indicate overall agreement between SMF-BIA and DXA for the estimation of ALM among older women with characteristics of sarcopenia, but SMF-BIA may overestimate or underestimate ALM in some individuals. These data suggest that SMF-BIA may be an acceptable alternative to DXA for the assessment of ALM in older women with characteristics of sarcopenia.

Keywords: Sarcopenia, DXA 


\section{INTRODUCTION}

Sarcopenia is defined as the progressive loss of muscle mass, physical function, and strength (i.e. dynapenia) which accelerates with aging [1-3]. Sarcopenia is associated with several adverse health outcomes among older adults including frailty, weakness, functional decline, increased risk of falls and fractures, and loss of independence $[1,2]$. In the year 2000, estimated healthcare costs associated with sarcopenia were $\$ 12.6$ billion for older men, and \$29.5 billion for older women [4]. The economic burden associated with sarcopenia is likely far higher today particularly in women, as they have a greater life expectancy and risk for functional impairment compared to men [5]. Although a universally accepted definition for sarcopenia is currently lacking, several working groups have convened to establish operational criteria for classification including measures of physical function, strength, and muscle mass.

While a wide range of techniques are available for assessing muscle mass, dual energy X-ray absorptiometry (DXA) is considered as the gold standard in research and clinical practice to determine appendicular lean mass (ALM) despite its limitations including exposure to radiation, expense, and lack of portability [2,6-8]. Thus, is it critical to find alternative methods for ALM assessment.

The use of segmental multi-frequency bioelectrical impedance analysis (SMFBIA) for the measurement of muscle mass has been accepted as a valid, more portable, and less expensive alternative in several populations [9-12] including older women $[13,14]$. While one study has validated the use of SMF-BIA for the estimation of ALM among a general population of older women [13], the device has not yet been 
validated for the assessment of ALM and its application to sarcopenia identification based on several accepted definitions. Thus, the purpose of this investigation was to assess whether SMF-BIA would accurately quantify ALM compared to DXA among a population of older women with characteristics of sarcopenia and/or dynapenia. It was hypothesized that SMF-BIA would be in agreement with DXA for the estimation of ALM. A secondary aim was to examine if SMF-BIA similarly classifies older women as sarcopenic compared to DXA based on ALM compared to height or body mass index (BMI) using established cut-points. 


\section{METHODS}

\section{Study Design}

The study utilized a cross-sectional design to compare differences between SMF-BIA and DXA for the estimation of ALM among 25 older women pre-screened for the presence of sarcopenia and/or dynapenia (reduced strength). The participants were pre-screened for entry into a 12-week University of Rhode Island Institutional Review Board approved, Resistance Exercise Study to Reclaim Lean Muscle and Strength (URI RESTORE ME Project: IRB \# HU1415-168). The two techniques being compared for this study were performed at baseline of the URI RESTORE ME project.

\section{Participants}

Community dwelling women $(n=25)$ aged 65 to 84 years were recruited from Rhode Island via flyers, newspaper ads, press releases, and by word of mouth within local senior centers. All women initially eligible based on information provided during a telephone screening were invited to an onsite orientation and pre-screening assessment. During pre-screening, all women provided written informed consent and were evaluated for the presence of sarcopenia and/or dynapenia determined from the assessment of lean mass, height, weight, grip strength, single chair stand, and gait speed based on the European Working Group on Sarcopenia in Older People (EWGSOP) and the Foundation for the National Institute of Health Sarcopenia Project (FNIHSP) criteria. The pre-screening visit determined that 38 participants were

eligible based on the sarcopenia criteria. Although eligible, 13 participants were 
subsequently eliminated from the final cohort due to questions of time commitment or orthopedic concerns that would limit full participation in the intervention phase of the project. Figure 1 summarizes each phase of study recruitment.

\section{Outcome Measures}

All testing sessions were standardized with participants arriving in the morning in a fasted state. Participants were instructed to arrive well hydrated and having not exercised. Both techniques for measuring body composition were performed on the same day, within the same hour, and following urine elimination. All participants were dressed in hospital scrubs for both methods.

Appendicular Lean Mass: ALM was estimated using fan-beam technology (GE Lunar iDXA, Waukesha, WI). The DXA scans were performed using a standardized procedure for patient positioning by a licensed radiology technician. The DXA scans provided estimations of ALM defined as the total skeletal muscle mass from the right arm, left arm, right leg, and left leg measured in kilograms.

In addition to DXA, a SMF-BIA was used to estimate segmental muscle mass whereby ALM could then be calculated. The InBody 570 Biospace device (Biospace Co, Ltd, Korea) was used according to the manufacturer's guidelines during both the pre-screening assessment (to determine sarcopenia status) and baseline testing to assess ALM. Body composition is estimated via SMF-BIA using the difference of conductivity of various tissues due to the differences in their biological characteristics. The risk of adverse events is low using SMF-BIA and its use has been performed safely on older adults in other studies [15]. As a precaution, women with a cardiac pacemaker or internal defibrillator were not tested. 
Sarcopenia Status: Prior to the collection of baseline testing data, participants completed pre-screening to determine their eligibility as presenting with sarcopenia and/or dynapenia. An algorithm for determining eligibility was developed based on a combination of both the EWGSOP and FNIHSP working definitions for sarcopenia. Initial ALM estimates using SMF-BIA in addition to outcomes of physical function using the gait speed, single chair stand, and grip strength tests were included in the algorithm. The cut-points established for each criteria included an ALM $<5.67 \mathrm{~kg} / \mathrm{m}^{2}$ or ALM/BMI $<0.512$, a grip strength $<20 \mathrm{~kg}$ or inability to complete a single chair stand, and a gait speed $<0.8 \mathrm{~m} / \mathrm{s}[2,16]$. Women selected were classified as having low lean mass (LM), low strength, low function (slow gait), or all three characteristics.

Physical Function: As part of the short physical performance battery (SPPB) of tests, usual gait speed was measured during pre-screening and during baseline to assess physical function and as a fundamental criterion for defining sarcopenia status. Gait speed has been suggested as being included in routine evaluations as the sixth vital sign [7] as it is a strong predictor of major health outcomes and survival in older adults [6]. The EWGSOP, International Working Group (IWG), and FNIHSP are all in agreement that a gait speed $<0.8 \mathrm{~m} / \mathrm{s}$ should be used as a cut-point for identifying sarcopenia in older adults $[2,16,18]$. Standardized protocols were utilized for administration of the gait speed test which required participants to walk 4 meters at a usual pace [19]. The test was repeated twice with the faster of the two trials recorded in seconds.

Muscle Strength: Grip strength is reliable, valid, and simple to administer in both clinical and community settings and is a predictor of mobility impairment 
[20,21]. Grip strength was tested during pre-screening and during baseline using a handgrip dynamometer (Jaymar Hydraulic Dynamometer, J.A. Preston, Corp., Jackson, MS). The test was performed with the participant seated in a chair with the elbow bent to 90 degrees using a standardized protocol [22]. The dynamometer was set accordingly based on each individual's hand size so that the second knuckle of all four fingers rested flat on the handle. Two trials were performed on each hand and the highest score was recorded in kilograms without accounting for hand dominance.

Grip strength values $<20 \mathrm{~kg}$ were also used as criteria for determining the presence of sarcopenia and/or dynapenia. Participants also completed a single chair stand test to assess lower body strength using a standardized protocol [23]. The test required that the participant rise from a chair with the arms crossed over the chest and with both feet flat on the floor. The ability or inability to rise from the chair was recorded and used to classify individuals as weak (i.e. dynapenia).

Anthropometrics: Each participant's height and weight were measured twice and the average of the two readings were used. Height and weight were measured with each participant barefoot and wearing hospital scrubs. Height was measured using a wall mounted stadiometer and weight was recorded using the InBody 570 SMF-BIA device. From these measurements, BMI was calculated by dividing the participants weight in kilograms by their height in meters squared.

\section{Other Measures}

Physical Activity: To assess each participant's physical activity level, the Yale Physical Activity Survey (YPAS) was administered during baseline testing. The YPAS quantifies the type and intensity of physical activity among older adults 
estimating total energy expenditure (kcals/week) and a total activity summary index. The YPAS has been shown to be a valid measurement for the assessment of physical activity among older adults [24]. The YPAS was used to describe physical activity patterns of the participant population.

Dietary Intake: Participants completed a Dietary Screening Tool (DST) developed for older adults at baseline to assess dietary patterns [25]. The DST identifies 3 levels of nutritional risk: at risk $(<60)$, at possible risk (60 to 75$)$, and not at risk (> 75) [26]. Nutritional risk assessed with the DST was used to describe the participant population.

\section{Statistical Analysis}

Estimated between-group differences were calculated for the primary outcomes, and a paired t-test was used to compare differences in estimated ALM by SMF-BIA and DXA. A previous study comparing SMF-BIA and DXA among frail women 75 years or older demonstrated an overall mean difference for ALM between the two techniques as $0.08 \pm 0.05 \mathrm{~kg}$ [13]. Based on the findings of this study, a sample size of 16 were required to provide sufficient power $(0.80)$ and alpha at 0.05 .

Clinical and demographic characteristics of the participants are expressed as mean \pm standard deviation. A Shapiro-Wilk test was performed to verify that data for the primary outcome variables were within normal distribution. To determine the strength of the relationship between the two variables, a Pearson moment correlation coefficient was performed. To test the primary hypothesis, a Bland-Altman method was employed to compare agreement between DXA and SMF-BIA whereby the 
differences in techniques are plotted against the averages of the two techniques [27]. To test the secondary hypothesis, a Fisher's exact test was used to compare sarcopenia status based on ALM between the two techniques. Statistical analyses were performed using SAS version 9.2 (SAS Institute Inc., Cary, NC, USA). 


\section{RESULTS}

A total of 25 female participants with a mean age of $72.3 \pm 4.6$ years were enrolled in this study. Demographic characteristics, anthropometric measures, indictors of physical functioning, physical activity, and dietary habits of the study population are summarized in Table 1.

A significant difference $(\mathrm{p}=0.0145)$ was observed between DXA and SMFBIA for the measurement of ALM by a mean of $0.5 \mathrm{~kg}$ for each participant. Additionally, a $4.3 \%$ error of ALM by SMF-BIA was observed compared to DXA as the gold standard $(\mathrm{p}=0.0162)$. A significant and strong positive correlation was observed between SMF-BIA and DXA as indicated by a Pearson's correlation coefficient of $0.88(95 \% \mathrm{CI}=0.75$ to $0.95, \mathrm{p}<0.001)$ highlighted in Figure 2 . In addition, agreement between the two methods was assessed using a Bland-Altman plot (Figure 3). A mean difference of $0.5 \mathrm{~kg}(95 \% \mathrm{CI}=-1.02$ to -0.02$)$ indicates overall agreement between SMF-BIA and DXA. However, SMF-BIA overestimated ALM for one participant $(-2.9 \mathrm{~kg}, 95 \% \mathrm{CI}=-3.76$ to -2.03$)$ and underestimated ALM for another participant $(1.8 \mathrm{~kg}, 95 \% \mathrm{CI}=0.98$ to 2.71$)$ compared to DXA.

When comparing sarcopenia status based on ALM measured by SMF-BIA and DXA, the Fisher's exact test indicates a significant difference $(\mathrm{p}<0.001)$ between the two techniques when using both the EWGSOP and FNIHSP criteria. Of the 25 women found to demonstrate characteristics of sarcopenia and/or dynapenia based on EWGSOP criteria during pre-screening, SMF-BIA identified less participants $(n=7)$ as sarcopenic compared to DXA $(n=11)$. While SMF-BIA and DXA similarly identified the normal and pre-sarcopenic participants, DXA was able to identify more 
participants as having sarcopenia based on current EWGSOP criteria (Table 2).

Similarly, DXA was able to identify more participants as having low lean mass $(\mathrm{n}=9)$ compared to SMF-BIA $(n=6)$ based on FNIHSP criteria (Table 3). 


\section{DISCUSSION}

The results of this study indicate overall agreement between SMF-BIA and DXA for the estimation of ALM among older women with characteristics of sarcopenia and/or dynapenia. A significant and strong correlation $(r=0.88)$ and the lack of significant difference between the two techniques indicates acceptability of SMF-BIA compared to DXA. The Bland Altman plot provided a visual judgement of agreement between techniques with a mean overestimation of ALM by SMF-BIA of $0.5 \mathrm{~kg}$. While most participants fell within the $95 \%$ limits of agreement, two outliers were identified. The plot indicates that SMF-BIA overestimated ALM but was not statistically different from DXA. The results of the present study are in line with previous studies which support that SMF-BIA is a valid, more portable, and affordable alternative to DXA for the estimation of ALM [7,9,10,13,14].

While the study indicates that SMF-BIA is a valid alternative to DXA, DXA appears to be more reliable for assessing ALM for diagnosing sarcopenia. Criteria for sarcopenia classification required that the participants ALM be $<5.67 \mathrm{~kg} / \mathrm{m}^{2}$ or ALM/BMI $<0.512$ in combination with weak grip strength $(<20 \mathrm{~kg})$ and/or slow gait speed $(<0.8 \mathrm{~m} / \mathrm{s})$. These findings suggest that SMF-BIA may overestimate ALM just enough to allow some participants to be above the sarcopenia ALM cut-off value. While the grip strength and gait speed functional outcomes stand alone to identify individuals at risk for sarcopenia, DXA is the most reliable method for identifying sarcopenic females based on ALM. Although overall agreement between SMF-BIA and DXA for the estimation of ALM was observed in this study, investigators should use caution when using some impedance models for diagnosing sarcopenia. 
In agreement with these findings, previous studies have demonstrated that SMF-BIA is a valid alternative to DXA for the estimation of ALM among healthy adult $[9,10]$ and older female participants $[13,14]$. Andersen et al. $[10]$ determined that similar SMF-BIA devices, namely the InBody 520 and 720, were valid for the estimation of ALM among healthy young women between the ages of 18 and 49 years. While both devices were strongly correlated to DXA, $(r=0.62-0.87)$ the conclusions were that SMF-BIA underestimated ALM by approximately $1.0 \mathrm{~kg}$ in the 25 female participants. Similar results were observed by Leahy et al. [9] with BIA underestimating arm and leg fat free mass by $0.2 \mathrm{~kg}(2.4 \%)$ and $0.8 \mathrm{~kg}(3.4 \%)$, respectively, in men and $0.2 \mathrm{~kg}(4.5 \%)$ and $0.7 \mathrm{~kg}(4.4 \%)$, respectively, in women (p $<0.001)$. Another similar study identified SMF-BIA as an appropriate alternative to DXA for the estimation of fat mass, percent body fat, and total lean mass, but not for the evaluation of ALM among a healthy adult population between 18 and 85 years [12]. Although the present study identifies the InBody 570 SMF-BIA device to be a valid alternative to DXA, the tendency for SMF-BIA to overestimate or underestimate ALM in some participants did occur as consistent with previous study findings.

Conflicting results regarding the agreement between SMF-BIA and DXA specifically for the measurement of ALM among elderly women have also been reported in other similar studies [7,13,14]. Buckinx et al. [7] observed low agreement between the two methods among approximately 25 women in the subcategory of participants over the age of $65(n=48)$ using a Bland-Altman plot method. The study reported a tendency for SMF-BIA to overestimate ALM by approximately $1.75 \mathrm{~kg}$ [7]. Other studies investigating older women report acceptable accuracy of SMF-BIA 
compared to DXA for the estimation of ALM. Among an older female Japanese population $(\mathrm{n}=330)$ aged 65 to 87 years old, SMF-BIA tended to underestimate ALM by $1.59 \mathrm{~kg}$ (95\% CI= 1.49 to 1.68$)$ [14]. Segmental multi-frequency BIA also provided acceptable accuracy for the estimation of ALM among frail women 75 years and older with a tendency to underestimate ALM $(r=-1.42, p<0.01)$ [13]. In the present study, despite significant differences in sarcopenia definitions between SMFBIA and DXA, the Bland-Altman plot indicated overall agreement between the two methods for the estimation of ALM with a mean difference of $0.5 \mathrm{~kg}$ among the older female participants.

This study has both strengths and weaknesses. The main strength was the use of standardized testing conditions. All participants were instructed to arrive for testing fasted, well hydrated, having not exercised, and following urine elimination. These confounding variables were well-controlled in addition to SMF-BIA and DXA being performed within the same hour. Hydration status upon arrival for testing was assessed based on self-report in addition to a normal ratio of extracellular water to total body water content (ECW/TBW) estimated by SMF-BIA. All participants ECW/TBW ratios were within the normal range of 0.36 to 0.39 as defined by the InBody manufacturer. The use of DXA as the gold standard method for body composition analysis by which SMF-BIA could be compared was an additional strength of the present study.

Potential limitations include the small sample size and homogeneity of the participant population as the results may not be generalizable to other populations. A larger sample size of older women including those from different racial, ethnic, and 
socioeconomic backgrounds could have demonstrated more similarity between SMFBIA and DXA using Fisher's exact analysis. The present study was limited to investigating the validity of only one of many SMF-BIA devices, the InBody 570. Additionally, the study was cross sectional therefore, future studies should examine changes in ALM longitudinally and following interventions. 


\section{CONCLUSION}

While previous studies have investigated the validity of SMF-BIA for estimation of ALM compared to DXA among older women, this is the first study to validate SMF-BIA in a population of older women who present with sarcopenia and/ or dynapenia. In conclusion, the present study confirmed overall agreement between SMF-BIA and DXA for the measurement of ALM among older women who present with characteristics of sarcopenia and/or dynapenia based on current definitions. It is possible however, that SMF-BIA may overestimate or underestimate ALM in some participants. While SMF-BIA is an acceptable, less expensive, and more portable alternative to DXA for measuring ALM, future studies are required using other devices and larger samples to justify that SMF-BIA is more realistic for clinical and epidemiological identification of sarcopenia based on current definitions. 


\section{REFERENCES}

1. Batsis JA, Mackenzie TA, Barre LK et al. Sarcopenia, sarcopenic obesity and mortality in older adults: results from the National Health and Nutrition Examination Survey III. Eur J Clin Nutr. 2014; 68(9): 1001-1007. doi:10.1038/ejcn.2014.117.

2. Cruz-Jentoft AJ, Baeyens JP, Bauer JM, et al. Sarcopenia: European consensus on definition and diagnosis: Report of the European Working Group on Sarcopenia in Older People. Age Ageing. 2010; 39(4): 412-423. doi:10.1093/ageing/afq034.

3. Tracy BL, Ivey FM, Hurlbut D, et al. Muscle quality. II. Effects of strength training in 65- to 75-yr-old men and women. J Appl Physiol. 1999; 86: 195-201.

4. Janssen I, Heymsfield SB, Baumgartner RN et al. Estimation of skeletal muscle mass by bioelectrical impedance analysis. J Appl Physiol. 2000; 89(2): 465471 .

5. Borst SE. Interventions for sarcopenia and muscle weakness in older people. Age Ageing. 2004; 33(6): 548-555. doi:10.1093/ageing/afh201.

6. Heymsfield SB, Gonzalez MC, Lu J et al. Skeletal muscle mass and quality: evolution of modern measurement concepts in the context of sarcopenia. Proc Nutr Soc. 2015; (December 2014): 1-12. doi:10.1017/S0029665115000129.

7. Buckinx F, Reginster J-Y, Dardenne N, et al. Concordance between muscle mass assessed by bioelectrical impedance analysis and by dual energy X-ray absorptiometry: a cross-sectional study. BMC Musculoskelet Disord. 2015; 16(1): 1-7. doi:10.1186/s12891-015-0510-9.

8. Cherin P, Voronska E, Fraoucene N et al. Prevalence of sarcopenia among healthy ambulatory subjects: the sarcopenia begins from 45 years. Aging Clin Exp Res. 2014; 26(2): 137-146. doi:10.1007/s40520-013-0132-8.

9. Leahy S, O'Neill C, Sohun R et al. A comparison of dual energy X-ray absorptiometry and bioelectrical impedance analysis to measure total and segmental body composition in healthy young adults. Eur J Appl Physiol. 2012; 112(2): 589-595. doi:10.1007/s00421-011-2010-4.

10. Anderson LJ, Erceg DN, Schroeder ET. Utility of multifrequency bioelectrical impedance compared with dual-energy x-ray absorptiometry for assessment of total and regional body composition varies between men and women. Nutr Res. 2012; 32(7): 479-485. doi:10.1016/j.nutres.2012.05.009.

11. Going S, Nichols J, Loftin M, et al. Validation of bioelectrical impedance analysis (BIA) for estimation of body composition in Black, White and Hispanic adolscent girls. Int J Body Compos Res. 2006; 4(4): 161-167. doi:10.2964/jsik.kuni0223.

12. Karelis AD, Chamberland G, Aubertin-Leheudre M et al. Validation of a 
portable bioelectrical impedance analyzer for the assessment of body composition. Appl Physiol Nutr Metab. 2013; 38(1): 27-32. doi:10.1139/apnm2012-0129.

13. Kim M, Kim H. Accuracy of segmental multi-frequency bioelectrical impedance analysis for assessing whole-body and appendicular fat mass and lean soft tissue mass in frail women aged 75 years and older. Eur J Clin Nutr. 2013; 67(4): 395-400. doi:10.1038/ejen.2013.9.

14. Kim M, Shinkai S, Murayama H et al. Comparison of segmental multifrequency bioelectrical impedance analysis with dual-energy X-ray absorptiometry for the assessment of body composition in a communitydwelling older population. Geriatr Gerontol Int. 2015; 15: 10131022.doi:10.1111/ggi.12384.

15. Whiteford J, Ackland TR, Dhaliwal SS, et al. Effects of a 1-year randomized controlled trial of resistance training on lower limb bone and muscle structure and function in older men. Osteoporos Int. 2010; 21(9): 1529-1536. doi:10.1007/s00198-009-1132-6.

16. Studenski S, Perera S, Patel K. Gait Speed and Survival in Older Adults. Jama. 2011; 305(1): 50-58. doi:10.1001/jama.2010.1923.Gait.

17. Fritz S, Lusardi M. White paper: "walking speed: the sixth vital sign". J Geriatr Phys Ther. 2009; 32(2): 46-49. doi:10.1519/00139143-200932020-00002.

18. Delmonico MJ, Beck DT. The Current Understanding of Sarcopenia : Emerging Tools and Interventional Possibilities. Am J Lifestyle Med. 2015; XX(X): 1-15. doi:10.1177/1559827615594343.

19. Goldberg A, Schepens S. Measurement error and minimum detectable change in 4-meter gait speed in older adults. Aging Clinical and Experimental Research. 2011; 23(5-6): 406-412.

20. McLean RR, Shardell MD, Alley DE, et al. Criteria for clinically relevant weakness and low lean mass and their longitudinal association with incident mobility impairment and mortality: The Foundation for the National Institutes of Health (FNIH) sarcopenia project. Journals Gerontol - Ser A Biol Sci Med Sci. 2014; 69 A(5): 576-583. doi:10.1093/gerona/glu012.

21. Cawthon PM, Fox KM, Gandra SR, et al. Clustering of strength, physical function, muscle and adiposity characteristics and risk of disability in older adults. J Am Geriatr Soc. 2011; 59(5): 781-787. doi:10.1111/j.15325415.2011.03389.x.Clustering.

22. Alley DE, Shardell MD, Peters KW, et al. Grip strength cutpoints for the identification of clinically relevant weakness. Journals Gerontol - Ser A Biol Sci Med Sci. 2014; 69 A(5): 559-566. doi:10.1093/gerona/glu011.

23. Roberts HC, Denison HJ, Martin HJ et al. A review of the measurement of grip strength in clinical and epidemiological studies: Towards a standardised 
approach. Age and Aging. 2011; 40; 423-429. doi: 10.1093/ageing/afr051.

24. Dipietro L, Caspersen CJ, Ostfeld AM et al. A survey for assessing physical activity among older adults. Med Sci Sports Exerc. 1993; 25(5): 628-642. http://www.ncbi.nlm.nih.gov/pubmed/8492692.

25. Bailey RL, Mitchell DC, Miller CK, et al. A dietary screening questionnaire identifies dietary patterns in older adults. J Nutr. 2007; 137(2): 421-426. doi:137/2/421 [pii].

26. Bailey RL, Miller PE, Mitchell DC et al. Dietary screening tool identifies nutritional risk in older adults. Am J Clin Nutr. 2009; 90(1): 177-183.

27. Bland JM, Altman DG. Statistical methods for assessing agreement between two methods of clinical measurement. Lancet. 1986; 1(8476): 307-310. doi:10.1016/S0140-6736(86)90837-8. 


\section{TABLES}

Table 1. Baseline Participant Characteristics

\begin{tabular}{|l|c|c|c|}
\hline & Mean (SD) & Minimum & Maximum \\
\hline Age & $72.3(4.6)$ & 66 & 81 \\
\hline Weight (kg) & $65.3(13.5)$ & 47 & 100.7 \\
\hline Height (cm) & $159.8(5.2)$ & 149.9 & 168.9 \\
\hline BMI (kg/m ${ }^{2)}$ & $25.7(5.8)$ & 18.9 & 42 \\
\hline \% Body Fat & $42.5(6.3)$ & 28.1 & 55.8 \\
\hline $\begin{array}{l}\text { Gait Speed } \\
\text { (meters/second) }\end{array}$ & $0.97(0.12)$ & 0.68 & 1.18 \\
\hline Grip Strength (kg) & $16.6(3.7)$ & 10 & 28 \\
\hline $\begin{array}{l}\text { Physical Activity } \\
\text { (kcals/week) }\end{array}$ & $6,912(3,270)$ & 1,183 & 13,350 \\
\hline $\begin{array}{l}\text { Physical Activity } \\
\text { Index }\end{array}$ & $49.6(22.1)$ & 16 & 103 \\
\hline $\begin{array}{l}\text { Dietary Patterns } \\
\text { *Abbreviation: BMI, Body Mass Index } \\
\text { *Physical Activity and dietary patterns derived from the Yale Physical Activity Survey } \\
\text { *Dietary Patterns derived from the Dietary Screening Tool } \\
\text { <60 = at risk, 60-75 = at possible risk, >75 = not at risk (Bailey et al., 2009) }\end{array}$ \\
\hline
\end{tabular}


Table 2. Fisher's Exact Test for Sarcopenia Classification Based on European

Working Group on Sarcopenia in Older People (EWGSOP) Definition Comparing

Segmental Multi-frequency Bioelectrical Impedance (SMF-BIA) and Dual Energy X-

ray Absportiometry (DXA)

\begin{tabular}{|c|c|c|c|c|c|}
\hline & $\begin{array}{l}\text { DXA } \\
\text { Normal }\end{array}$ & $\begin{array}{l}\text { DXA Pre- } \\
\text { Sarcopenia }\end{array}$ & $\begin{array}{l}\text { DXA } \\
\text { Sarcopenia }\end{array}$ & $\begin{array}{l}\text { DXA } \\
\text { Weak }\end{array}$ & Total \\
\hline $\begin{array}{l}\text { SMF-BIA } \\
\text { Normal }\end{array}$ & 3 & 0 & 0 & 0 & 3 \\
\hline $\begin{array}{l}\text { SMF-BIA Pre- } \\
\text { Sarcopenia }\end{array}$ & 0 & 1 & 0 & 0 & 1 \\
\hline $\begin{array}{l}\text { SMF-BIA } \\
\text { Sarcopenia }\end{array}$ & 0 & 0 & 7 & 0 & 7 \\
\hline $\begin{array}{l}\text { SMF-BIA } \\
\text { Weak }\end{array}$ & 0 & 0 & 4 & 10 & 14 \\
\hline Total & 3 & 1 & 11 & 10 & 25 \\
\hline \multicolumn{6}{|c|}{$\begin{array}{l}\text { *Normal }=\text { ALM }>5.67 \mathrm{~kg} / \mathrm{m}^{2}, \text { Grip Strength }>20 \mathrm{~kg} \text {, and Gait Speed }>0.8 \mathrm{~m} / \mathrm{s} \\
\text { *Pre-Sarcopenia }=\text { ALM }<5.67 \mathrm{~kg} / \mathrm{m}^{2} \text {, Grip strength }>20 \mathrm{~kg} \text {, and Gait Speed }>0.8 \mathrm{~m} / \mathrm{s} \\
\text { *Sarcopenia }=\text { ALM }<5.67 \mathrm{~kg} / \mathrm{m}^{2} \text { and Grip }<20 \mathrm{~kg} \text { or Gait Speed }<0.8 \mathrm{~m} / \mathrm{s} \\
\text { *Weak }=\text { ALM }>5.67 \mathrm{~kg} / \mathrm{m}^{2} \text { and Grip }<20 \mathrm{~kg} \\
\text { NOTE: Significant difference between definitions }(\mathrm{p}<0.001)\end{array}$} \\
\hline
\end{tabular}


Table 3. Fisher's Exact Test for Sarcopenia Classification Based on the Foundation for the National Institute of Health Sarcopenia Project (FNIHSP) Definition Comparing Segmental Multi-frequency Bioelectrical Impedance (SMF-BIA) and Dual Energy X-ray Absportiometry (DXA)

\begin{tabular}{|l|l|l|l|l|}
\hline & $\begin{array}{l}\text { DXA } \\
\text { Low } \\
\text { Lean }\end{array}$ & $\begin{array}{l}\text { DXA } \\
\text { Normal }\end{array}$ & $\begin{array}{l}\text { DXA } \\
\text { Weak }\end{array}$ & Total \\
\hline $\begin{array}{l}\text { SMF-BIA Low } \\
\text { Lean }\end{array}$ & 6 & 0 & 0 & 6 \\
\hline $\begin{array}{l}\text { SMF-BIA } \\
\text { Normal }\end{array}$ & 3 & 7 & 0 & 10 \\
\hline $\begin{array}{l}\text { SMF-BIA } \\
\text { Weak }\end{array}$ & 0 & 0 & 9 & 9 \\
\hline Total & 9 & 7 & 9 & 25 \\
\hline $\begin{array}{l}\text { *Normal = ALM > 15.02 kg or ALM/BMI > 0.512 and Grip Strength > } 16 \mathrm{~kg} \\
\text { *Low Lean = ALM < 15.02 kg or ALM/BMI < 0.512 and Grip > } 16 \mathrm{~kg} \\
\text { *Weak = ALM > 15.02 kg or ALM/BMI > 0.512 and Grip < } 16 \mathrm{~kg} \\
\text { NOTE: Significant difference between definitions (p < 0.001) }\end{array}$ \\
\hline
\end{tabular}




\section{FIGURES}

Figure 1. Study Flow Chart

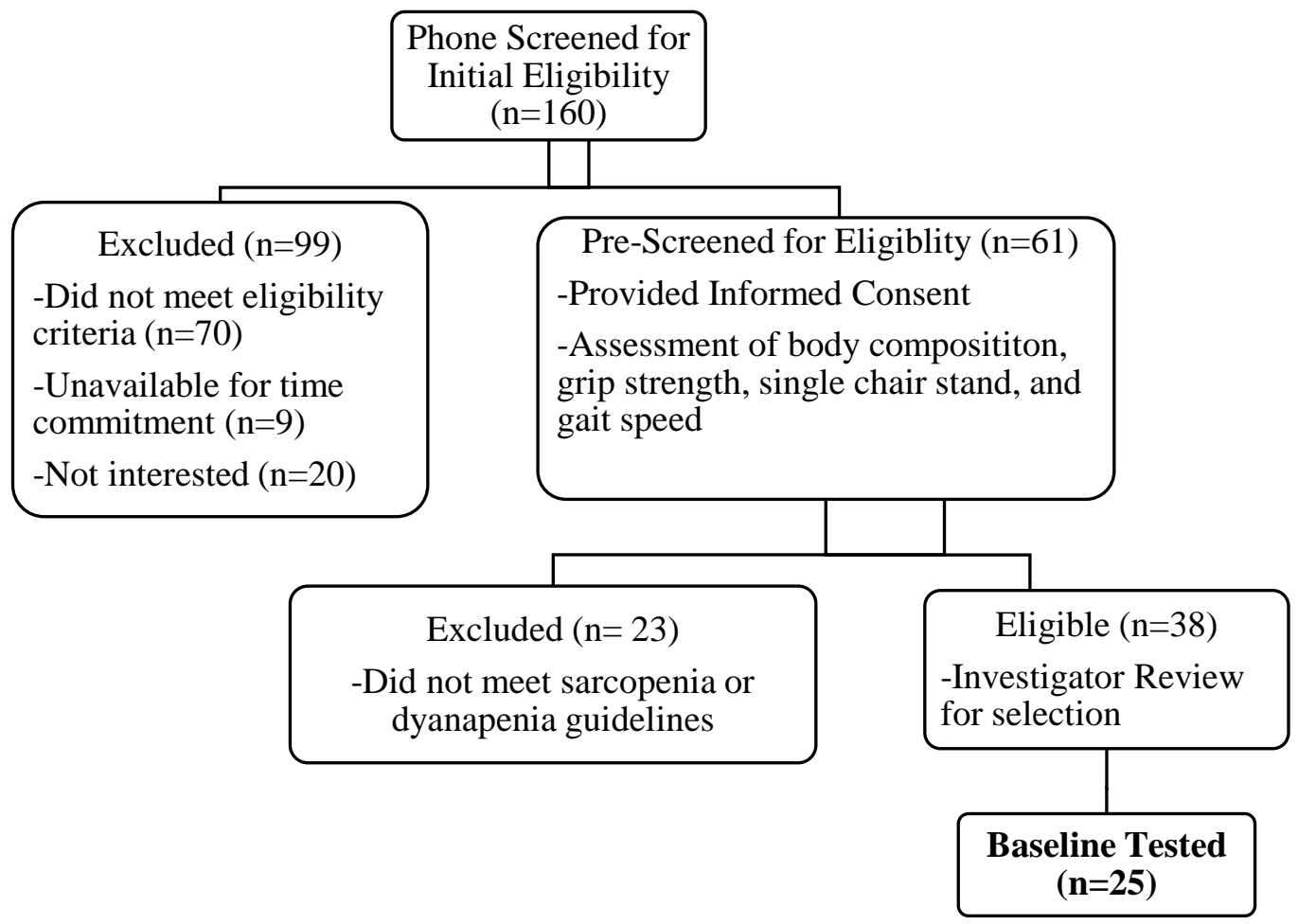


Figure 2. Pearson's Correlation Coefficient Between Segmental Multi-frequency Bioelectrical Impedance (SMF-BIA) and Dual Energy X-ray Absorptiometry (DXA) for the Measurement of Appendicular Lean Mass (ALM)

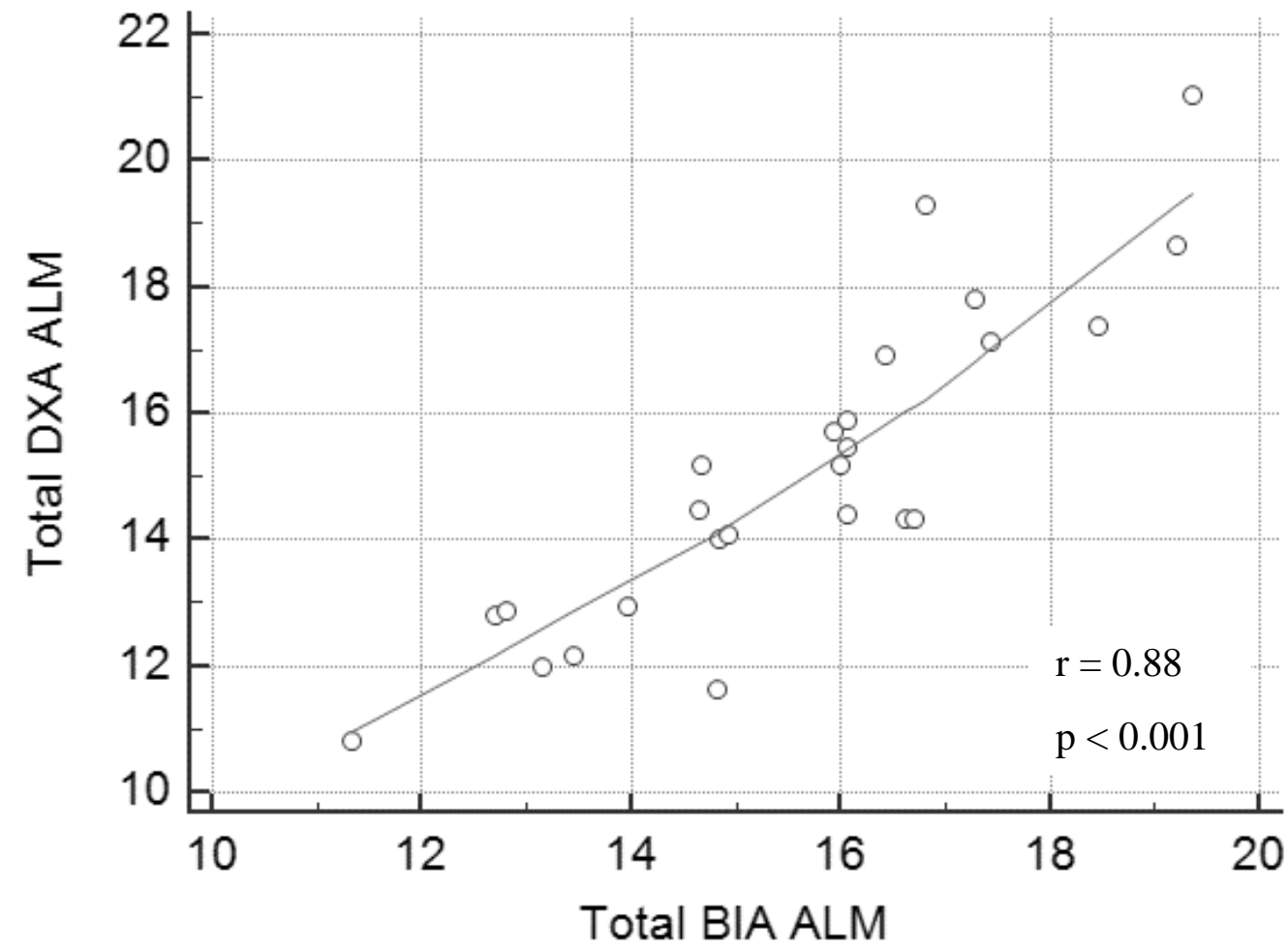

*A significant and strong positive correlation was observed between SMF-BIA and DXA with a correlation coefficient of $0.88(95 \% \mathrm{CI}=0.75$ to 0.95 , $\mathrm{p}<0.001)$. 
Figure 3. Bland-Altman Plot Comparing Appendicular Lean Mass (ALM) by

Segmental Multi-frequency Bioelectrical Impedance (SMF-BIA) and Dual Energy Xray Absorptiometry (DXA)

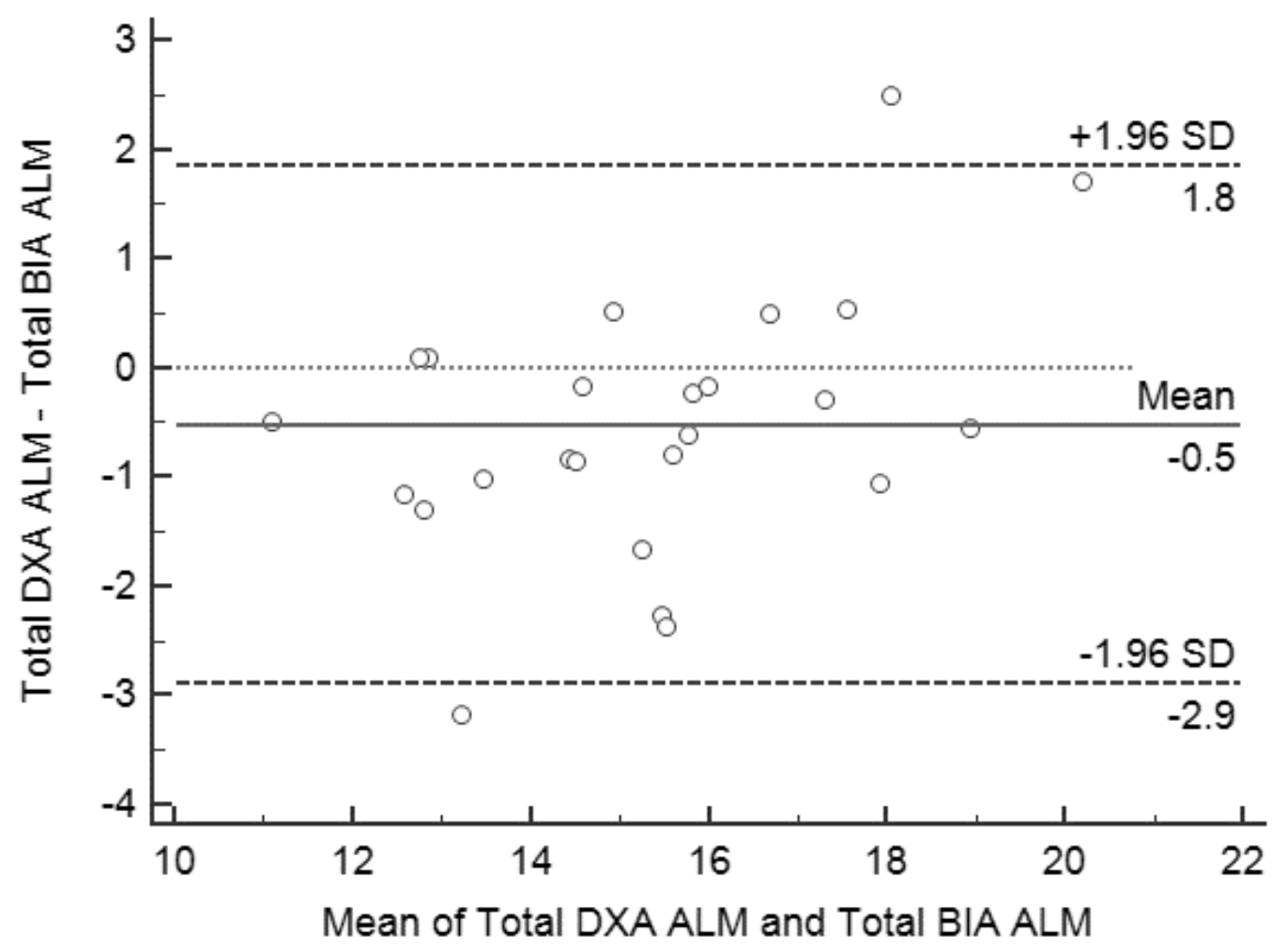

*A mean difference of $0.5 \mathrm{~kg}(95 \% \mathrm{CI}=-1.02$ to -0.02$)$ indicates overall agreement between SMF-BIA and DXA.

*SMF-BIA overestimated ALM for one participant ( $-2.9 \mathrm{~kg}, 95 \% \mathrm{CI}=-3.76$ to -2.03$)$ and underestimated ALM for another participant $(1.8 \mathrm{~kg}, 95 \% \mathrm{CI}=0.98$ to 2.71$)$ compared to DXA. 


\title{
APPENDICES
}

\section{Appendix A: Review of the Literature}

\begin{abstract}
The loss of muscle mass associated with advancing age, termed sarcopenia, contributes to the development of physical disability and mobility limitation. Women are at a greater risk for developing physical disability compared to men as patterns of functional impairment related to the loss of muscle and strength (i.e. dynapenia) differ between genders. Although a universally accepted definition for sarcopenia is lacking, several working groups have established criteria based on low appendicular lean mass (ALM) and poor physical function. While dual energy x-ray absorptiometry (DXA) is considered as the gold standard method for measuring ALM, several studies have validated the use of segmental multi-frequency bioelectrical impedance (SMF-BIA) as a more portable alternative. No study to date has assessed the accuracy of SMF-BIA among older women who present with characteristics of sarcopenia and/or dynapenia.
\end{abstract}

\section{Introduction}

Sarcopenia is defined as the progressive loss of muscle mass, physical

function, and strength (i.e. dynapenia) which accelerates with advancing age. ${ }^{1-3}$ The mechanisms for sarcopenia are multifactorial and include physical inactivity, malnutrition, hormonal changes, denervation of motor units, and the conversion of fast type II muscle fibers to slow type I muscle fibers, among others. ${ }^{2,4}$ As a natural 
process of aging, muscle mass declines by approximately 1 to $2 \%$ per year after age 50 contributing to the loss of strength at an even greater rate. ${ }^{1,5,6}$ Muscle strength has been reported to decline 2 to 5 times faster than muscle mass with age contributing to poor physical function, mobility limitation, and disbaility. ${ }^{7-9}$ Sarcopenia is associated with several adverse health outcomes among older adults including frailty, weakness, functional decline, increased risk of falls and fractures, and loss of independence. ${ }^{1,2}$ Moreover, in the year 2000, estimated healthcare costs associated with sarcopenia were $\$ 12.6$ billion for older men, and $\$ 29.5$ billion for older women. ${ }^{10}$ The economic burden associated with sarcopenia is likely far higher today particularly in women, as they have a greater life expectancy and risk for functional impairment compared to men. ${ }^{11,12}$

Although there is currently no universal definintion for identifying sarcopenic individuals, several working groups have established cut-points for low lean mass in addition to markers of reduced physical functioning and muscle strength. While early definitions were based exclusively on muscle mass compared to a healthy reference population, ${ }^{13}$ the current definitions also consider performance criteria. The European Working Group on Sarcopenia in Older People (EWGSOP), the Foundation for the National Intistutes of Health Sarcopenia Project (FNIHSP), and the International Working Group (IWG) are all in agreement that ALM in combination with weak grip strength and or slow gait speed be present to confirm sarcopenia status.

While a wide range of techniques are available for assessing muscle mass, DXA is considered as the gold standard in research and clinical practice to determine ALM despite its limitations including exposure to radiation, expense, and lack of 
portability. ${ }^{2,14,15,4}$ Thus, is it critical to find alternative methods for ALM assessment. The use of segmental multi-frequency bioelectrical impedance analysis (SMF-BIA) for the measurement of muscle mass has been accepted as a valid, more portable, and less expensive alternative in several populations ${ }^{16-19}$ including older women. ${ }^{20,21}$ While some studies have validated the use of SMF-BIA for the estimation of ALM among older women, ${ }^{20}$ the device has not yet been validated for the assessment of sarcopenia based on current international definitions.

\section{Sarcopenia in Older Women}

Women represent the largest proportion of the elderly, and their patterns of functional impairment related to declines in muscle mass and strength differ from men. ${ }^{12}$ Women are at a greater risk for developing decreased muscle strength (dynapenia) and sarcopenia with aging which also increases their risk for mortality compared to men as they have more fat, lower absolute muscle mass, and less strength. ${ }^{1,22}$ The earlier development of muscle weakness observed in women compared to men can be partially explained by menopause as a reduction in the sexhormone estrogen is associated with loss of bone mass and strength. ${ }^{11,23}$ Changes in the sex hormones estrogen and progesterone begin a decade or more prior to menopause, which may accelerate the morphological changes in skeletal muscle characteristic of sarcopenia. Consequently, post-menopausal women present with half the concentration of estrogen observed before menopause thus increasing their incidence of sarcopenia. ${ }^{24}$ 
Women also experience earlier declines in muscle power at a rate of 3 to $4 \%$ faster than strength compared to men. ${ }^{24}$ Early declines in muscle power, defined as the ability to perform muscular work per unit of time could explain the variance in poorer physical function and subsequent disability. ${ }^{24,25}$ A longitudinal study followed 545 high-functioning women aged 75 years and older over a seven-year period to determine which baseline activities of daily living were most strongly predictive of future disability. Women with poor mobility measured by time to complete five chair stands, gait speed, and number of steps to walk 6 meters had odds ratios $(95 \% \mathrm{CI})$ equal to $7.62(3.86,15.04), 6.31(3.26,12.19)$ and $5.31(2.43,11.59)$, respectively, for developing disability while women with poor grip strength had $2.81(1.43,5.52)$ times the risk of developing disability. ${ }^{12}$ Given that women experience a greater life expectancy as well as greater functional impairment associated with muscle weakness, early identification of muscle loss using accurate and clinically available techniques is especially important so that appropriate interventions can be delivered to reduce adverse health outcomes and improve quality of life. ${ }^{11}$

\section{Working Definitions for Sarcopenia}

Screening individuals for clinically significant sarcopenia has presented as a major challenge for the justification of intervention strategies that could reduce disability among older adults without a universally accepted definition. As a result, several working groups have convened to establish criteria to identify individuals at risk in order to prevent adverse events associated with reduced lean mass (LM) and physical function. ${ }^{13,26}$ Muscle mass can be quantified using DXA, SMF-BIA, and 
anthropometry while muscle strength can be measured most effectively by testing handgrip strength using a handheld dynamometer. ${ }^{27}$ In clinical practice, physical performance is measured using the short physical performance battery (SPPB) of tests, the get up and go test, and gait speed. The most prominent statements defining sarcopenia based on low muscle mass and physical function have come from the European Working Group on Sarcopenia in Older People (EWGSOP), International Working Group (IWG), and the Foundation for the National Institutes of Health Sarcopenia Project (FNIHSP). While early definitions were based exclusively on muscle mass compared to a healthy reference population, the current definitions also consider performance criteria. ${ }^{13}$

The EWGSOP algorithm requires that low muscle mass accompanied by either low grip strength, slow gait speed, or a combination of all three be present for classification of pre-sarcopenia, sarcopenia, or severe sarcopenia. ${ }^{2,13}$ The EWGSOP defines low muscle mass as an ALM in kilograms relative to height squared $\left(\mathrm{kg} / \mathrm{m}^{2}\right)$ less than $7.23 \mathrm{~kg} / \mathrm{m}^{2}$ in men and less than $5.67 \mathrm{~kg} / \mathrm{m}^{2}$ in women. Their cutoff values for low grip strength are set at less than $30 \mathrm{~kg}$ in men and less than $20 \mathrm{~kg}$ in women. In order to be considered slow, and individual must present with a gait speed less than 0.8 meters per second $(\mathrm{m} / \mathrm{s})$. Based on the results from screening of the above mentioned criteria, the severity of sarcopenia may be determined. Pre-Sarcopenia is defined by low muscle mass without low muscle strength whereas severe sarcopenia is defined by demonstrating all three criteria. Individuals with sarcopenia present with low muscle mass in combination with either low grip strength or slow gait speed. 
The International Working Group defines sarcopenia as the age related loss of skeletal muscle mass and function caused by several factors including disuse, altered endocrine function, chronic diseases, inflammation, insulin resistance, and nutritional deficiencies which contribute to disability, hospitalization, and death. ${ }^{28}$ The group considers that all older patients who present with observed decrements in physical function, strength, and overall health be evaluated. Their diagnosis of sarcopenia is based on the presence of low whole body or ALM in combination with poor physical functioning. Similar to the EWGSOP criteria, the IWG confirms diagnosis of sarcopenia based on the same ALM criteria however, their cut-points are less conservative with slow gait speed defined as less than $1.0 \mathrm{~m} / \mathrm{s}^{28}$

Rather than define sarcopenia, the FNIH have proposed a two-step clinical paradigm to identify individuals with low muscle strength and low muscle mass by first screening for mobility impairment and low muscle strength measured by gait speed and grip strength, respectively. ${ }^{13,29}$ The FNIHSP recommends that individuals be identified using either "weak with low LM" or "weak and slow with low LM" rather than use the term sarcopenia. ${ }^{30}$ The group is in agreement with the EWGSOP and IWG on the use of a cut-point for slow gait speed defined as less than $0.8 \mathrm{~m} / \mathrm{s}$, as it is easy to measure in most settings and is highly predictive of survival and major health outcomes. ${ }^{31}$ The cut-points established to identify weak individuals based on a grip strength are set as less than $26 \mathrm{~kg}$ in men and less than $16 \mathrm{~kg}$ in women compared to the EWGSOP criteria ( $<30 \mathrm{~kg}$ in men and $<20 \mathrm{~kg}$ in women). ${ }^{32}$ Their criteria for low LM is defined as an ALM $<19.75 \mathrm{~kg}$ for men and $<15.02 \mathrm{~kg}$ for women and the criteria for low LM based on the ratio of ALM relative to body mass index (BMI) is 
defined as $<0.789$ in men and $<0.512$ in women. ${ }^{30,33}$ The prevalence of sarcopenia in adults over 50 varies greatly depending on the definition being used therefore, adoption of an operational definition is required for effective prevention and treatment strategies to be implemented. ${ }^{2}$ A universally accepted sarcopenia definition would allow effective interventions to be delivered to at risk individuals identified using a variety of screening techniques for low ALM and low physical function.

\section{Evolution of Body Composition Evaluation Techniques}

Since the birth of early methods for assessing body composition, several advancements in the techniques for providing accurate regional and total body estimates of skeletal muscle mass have become widely available. Within a very short time span in the early 1970s, all three contemporary clinical and reference methods, computerized axial tomography (CT), magnetic resonance imaging (MRI), and DXA came into existence. ${ }^{34}$ Early methods (CT and MRI) have more recently developed into refined methods that have the ability to quantify regional and total body skeletal muscle mass including bioelectrical impedance analysis (BIA) and DXA, all of which have advantages and disadvantages. ${ }^{14}$

Three dimensional imaging techniques including CT and MRI have the ability to quantify all major tissues in the human body. Computerized axial tomography consists of a rotating X-ray tube and detector, which move in a perpendicular plane to the subject. The difference in the attenuation or weakening of the x-rays as they penetrate body tissues determines the density of the underlying tissues. The attenuated 
$\mathrm{X}$-ray beams can then generate a computer image of the scanned area separating bone, adipose tissue, and lean tissue. An advantage of CT is its ability to construct highquality images providing a measure of tissue composition and quality however, the degree of radiation exposure and relatively high cost limits its use in research and clinical settings. ${ }^{14}$ Unlike CT scanning, MRI does not use radiation; rather it creates images from radio frequency signals emitted by hydrogen nuclei. The fundamental MRI concept is based on interaction between nuclei of abundant hydrogen atoms and magnetic fields produced and controlled by the system's instrumentation. Application of an external magnetic field followed by a pulsed radio frequency across a body part causes the hydrogen nuclei to line up and absorb energy. When the radio wave is turned off, the nuclei emit the energy previously absorbed thus, emitting a signal that can then be used to create an image. While CT and MRI are accepted as accurate measures of whole body composition, neither are available or affordable methods for conducting sarcopenia trials. ${ }^{34,35}$

Although CT and MRI provide the most accurate assessment of body composition, these reference methods have several limitations including expense, equipment availability, and excessive radiation exposure with $\mathrm{CT},{ }^{36}$ therefore DXA has been used more frequently due to its relatively low cost and minimal radiation exposure. ${ }^{34,37}$ DXA uses an X-ray tube to evaluate bone mineral density and soft tissue composition. The attenuation of the x-rays with high and low photon energies is measurable and dependent on the thickness, density, and chemical composition of the underlying tissue. ${ }^{35}$ The scan has the ability to evaluate fat, lean soft tissue, and bone separately for the extremities, trunk, and other selected body regions. This segmental 
analysis can then allow estimation of ALM for assessing skeletal muscle loss with aging. ${ }^{34}$ The availability of DXA, its modest scan cost, low radiation exposure, short scan time, and the extensive information provided from each scan has ultimately led to this approach being most widely used in sarcopenia research and clinical practice today. ${ }^{14}$

While DXA is the most widely used method for assessing body composition, the use of BIA has grown rapidly in the past two decades as a noninvasive, portable, quick, and inexpensive alternative. Bioelectrical impedance analysis is based on the relation between the volume of a conductor and its electrical resistance, therefore skeletal muscle is a dominant conductor because it is an electrolyte rich tissue with low resistance. ${ }^{10}$ The devices deliver an alternating current at one or more frequencies via electrodes, and impedance to electrical flow is detected. Electrolyte-rich fluids such as body water pose the least impedance to electrical flow, while lipids and bone minerals provide the most. The traditional whole body, single frequency models have evolved into segmental multi-frequency models which can measure resistance for each body segment at a wide range of frequencies. ${ }^{38}$ The use of SMF-BIA has become more common as segmental analysis of the arm and leg can be empirically calibrated to DXA appendicular lean mass however, stable subject conditions are required for accurate results. ${ }^{10,14}$

\section{Comparison between BIA and DXA}

Although several techniques for measuring body composition are available in research and clinical practice, DXA is considered to be the gold standard due to its 
precision for distinguishing fat, bone, and muscle tissue. ${ }^{2,39}$ As an alternative to CT scans and MRI, DXA became available in 1987 as a more practical method with limited radiation exposure. ${ }^{34}$ The ability to isolate body regions during DXA analysis allowed many investigators the opportunity to evaluate fat, lean soft tissue, and bone mineral content separately for the extremities, trunk, and other selected body regions. With the introduction of portable SMF-BIA devices, the same segmental body composition analysis could be estimated with no exposure to radiation and at a very low cost. ${ }^{2,17,40}$ While earlier studies supported the validation of DXA using prediction equations for the estimation of ALM, future studies would successfully validate the use of these prediction equations by BIA. ${ }^{41}$

While studies prior to 2003 identified good correlation between BIA and MRI using prediction equations, these equations for the estimation of ALM by BIA compared to DXA did not yet exist. Validation of a BIA equation to predict ALM compared to DXA was performed by Kyle et al. ${ }^{42}$ among 444 participants aged 22 to 94 years. Using a single frequency bioelectrical impedance device (SF-BIA), a single prediction equation taking into account predictor variables including, height ${ }^{2} /$ resistance, weight, gender, age, and reactance was used for each participant. The results indicated that DXA measured ALM was strongly correlated to the BIA derived resistance normalized for height, and that BIA was valid for estimating ALM with a standard error between 5\% and 7.5\% (1.1 kg and $1.5 \mathrm{~kg})$. While several similar prediction equations by BIA have been published and validated against DXA for the estimation of skeletal muscle mass (SMM), general BIA prediction equations across different ages, ethnic groups, and clinical conditions had not yet been tested. ${ }^{10,42,43}$ 
The aim of a study performed by Boseaus et al. ${ }^{44}$ was to validate SF-BIA prediction equations developed previously for estimating SMM among 86 male and 66 female Australian patients with clinical disorders aged 70 and over compared to DXA.

Overall, the study demonstrated that SF-BIA, using a prediction equation, gave an accurate estimate of DXA derived SMM among participants with a standard error of $1.68 \mathrm{~kg}$. With the introduction of validated prediction equations for the estimation of total SMM and ALM using BIA, several studies could then investigate the validity of several types of single and multi-frequency BIA models among several populations compared to DXA.

Numerous studies have investigated the validity of several bioelectrical impedance devices for the measurement of ALM compared to DXA among several populations with conflicting results. In a study by Leahy et al. ${ }^{16}$ in a healthy adult population $(n=403)$ aged 18 to 29 years, overall agreement between SMF-BIA (Tanita MC-180MA) and DXA for the measurement of ALM was observed. Anderson et al. ${ }^{17}$ also reported agreement between SMF-BIA (InBody720) and DXA among the 25 women aged 18 to 49 years for the estimation of ALM however, among the 25 men, an underestimation of ALM of approximately $3.0 \mathrm{~kg}$ was observed. ${ }^{17}$ Another similar study identified SMF-BIA (InBody230) as an appropriate alternative to DXA for the estimation of fat mass, percent body fat, and total LM but not for the evaluation of ALM among a healthy adult population between 18 and 85 years. ${ }^{19}$ While many studies report overall agreement between SMF-BIA and DXA, there appears to be consistent observation of a systematic bias with either overestimation or underestimation of ALM with some devices. 
While several studies report overall agreement between several SMF-BIA devices among healthy adult populations, others aimed to validate BIA devices among older women. Of the studies that include older women, conflicting results regarding the agreement between SMF-BIA and DXA specifically for the measurement of ALM have also been observed. ${ }^{15,20}$ Buckinx et al. ${ }^{15}$ observed low agreement between SMFBIA (InBody S10) and DXA among approximately 25 women in the subcategory of participants over the age of $65(n=48)$ using a Bland-Altman plot method. The study reported strong agreement for LM of the upper limbs and low agreement for LM in the lower limbs between the two techniques with a tendency for SMF-BIA to overestimate ALM by approximately $1.75 \mathrm{~kg} .{ }^{15}$ The participants in the subcategory over the age of 65 years were more frequently outside the limits of agreement, therefore more participants of this age group may have been required for overall agreement to be observed. In a similar study by Kim et al. ${ }^{45}$ a larger population of community dwelling older men $(n=241)$ and women $(n=331)$ aged 65 to 87 years were included to investigate the validity of SMF-BIA (InBody 720) compared to DXA. The findings of this study compare to previous studies reporting good agreement between the two methods for the estimation of ALM, although SMF-BIA had a tendency to underestimate ALM among female participants with a bias of $1.59 \mathrm{~kg}$ (95\% CI 1.49 to 1.68). ${ }^{45}$ A study by Kim et al. ${ }^{20}$ also reported agreement between SMF-BIA (InBody 720) and DXA among 129 frail community dwelling Japanese women aged 75 to 89 years. ${ }^{20}$ Kim et al. ${ }^{20}$ are the first to assess the validation of SMF-BIA for the measure of ALM in a heterogeneous older female participant population. In order to fill the current gap in the literature, future research efforts should investigate the accuracy of 
other SMF-BIA devices among older Caucasian women for the measurement of ALM as a criterion for sarcopenia classification.

\section{Conclusions}

While some studies have reported overall agreement between SMF-BIA and DXA for the estimation of ALM among older women, others have reported conflicting results. Additional studies are required to confirm agreement between DXA and SMF-BIA under standardized testing conditions that may reduce the systematic bias reported by previous investigators. Despite the evidence in support of SMF-BIA accurately estimating ALM, no study to date has investigated the agreement between SMF-BIA and DXA among participants with characteristics of sarcopenia and/or dynapenia based on current international definitions. Future studies investigating the validation of SMF-BIA compared to DXA for accurate sarcopenia classification based on established criteria for low LM based on ALM are also required. Validation of SMF-BIA among populations of older women would provide a more portable and less expensive alternative to DXA for clinical and epidemiological screening for sarcopenia based on the measurement of ALM in addition to tests of physical function.

\section{References:}

1. Batsis JA, Mackenzie TA, Barre LK, Lopez-Jimenez F, Bartels SJ. Sarcopenia, sarcopenic obesity and mortality in older adults: results from the National Health and Nutrition Examination Survey III. Eur J Clin Nutr. 2014; 68(9): 1001-1007. doi:10.1038/ejcn.2014.117.

2. Cruz-Jentoft AJ, Baeyens JP, Bauer JM, et al. Sarcopenia: European consensus 
on definition and diagnosis: Report of the European Working Group on Sarcopenia in Older People. Age Ageing. 2010; 39(4): 412-423.

doi:10.1093/ageing/afq034.

3. Tracy BL, Ivey FM, Hurlbut D, et al. Muscle quality II. Effects of strength training in 65- to 75-yr-old men and women. J Appl Physiol. 1999; 86: 195-201.

4. Cherin P, Voronska E, Fraoucene N, de Jaeger C. Prevalence of sarcopenia among healthy ambulatory subjects: the sarcopenia begins from 45 years. Aging Clin Exp Res. 2014; 26(2): 137-146. doi:10.1007/s40520-013-0132-8.

5. Cawthon PM, Fox KM, Gandra SR, et al. Clustering of strength, physical function, muscle and adiposity characteristics and risk of disability in older adults. J Am Geriatr Soc. 2011; 59(5): 781-787. doi:10.1111/j.15325415.2011.03389.x.Clustering.

6. Choi KM. Sarcopenia and Sarcopenic Obesity. Endocrinol Metab. 2013; 28: 86-89.

7. Delmonico MJ, Harris TB, Visser M, et al. Longitudinal study of muscle strength, quality, and adipose tissue infiltration. Am J Clin Nutr. 2009; 90(6): 1579-1585. doi:10.3945/ajcn.2009.28047.

8. Hughes VA, Frontera WR, Wood M, et al. Longitudinal muscle strength changes in older adults: influence of muscle mass, physical activity, and health. J Gerontol A Biol Sci Med Sci. 2001; 56(5): B209-B217. doi:10.1093/gerona/56.5.B209.

9. Visser M, Goodpaster BH, Kritchevsky SB, et al. Muscle mass, muscle strength, and muscle fat infiltration as predictors of incident mobility limitations in well-functioning older persons. J Gerontol A Biol Sci Med Sci. 2005; 60(3): 324-333. doi:10.1093/gerona/60.3.324.

10. Janssen I, Heymsfield SB, Baumgartner RN, Ross R. Estimation of skeletal muscle mass by bioelectrical impedance analysis. J Appl Physiol. 2000; 89(2): 465-471.

11. Borst SE. Interventions for sarcopenia and muscle weakness in older people. Age Ageing. 2004; 33(6): 548-555. doi:10.1093/ageing/afh201.

12. Carrière I, Colvez A, Favier F, Jeandel C, Blain H. Hierarchical components of physical frailty predicted incidence of dependency in a cohort of elderly women. J Clin Epidemiol. 2005; 58(11): 1180-1187. doi:10.1016/j.jclinepi.2005.02.018.

13. Correa-De-Araujo R, Hadley E. Skeletal muscle function deficit: A new 
terminology to embrace the evolving concepts of sarcopenia and age-related muscle dysfunction. Journals Gerontol - Ser A Biol Sci Med Sci. 2014; 69 A(5): 591-594. doi:10.1093/gerona/glt208.

14. Heymsfield SB, Gonzalez MC, Lu J, Jia G, Zheng J. Skeletal muscle mass and quality: evolution of modern measurement concepts in the context of sarcopenia. Proc Nutr Soc. 2015; (December 2014): 1-12. doi:10.1017/S0029665115000129.

15. Buckinx F, Reginster J-Y, Dardenne N, et al. Concordance between muscle mass assessed by bioelectrical impedance analysis and by dual energy X-ray absorptiometry: a cross-sectional study. BMC Musculoskelet Disord. 2015; 16(1): 1-7. doi:10.1186/s12891-015-0510-9.

16. Leahy S, O'Neill C, Sohun R, Jakeman P. A comparison of dual energy X-ray absorptiometry and bioelectrical impedance analysis to measure total and segmental body composition in healthy young adults. Eur J Appl Physiol. 2012; 112(2): 589-595. doi:10.1007/s00421-011-2010-4.

17. Anderson LJ, Erceg DN, Schroeder ET. Utility of multifrequency bioelectrical impedance compared with dual-energy $\mathrm{x}$-ray absorptiometry for assessment of total and regional body composition varies between men and women. Nutr Res. 2012; 32(7): 479-485. doi:10.1016/j.nutres.2012.05.009.

18. Going S, Nichols J, Loftin M, et al. Validation of bioelectrical impedance analysis (BIA) for estimation of body composition in Black, White and Hispanic adolscent girls. Int J Body Compos Res. 2006; 4(4): 161-167. doi:10.2964/jsik.kuni0223.

19. Karelis AD, Chamberland G, Aubertin-Leheudre M, Duval C. Validation of a portable bioelectrical impedance analyzer for the assessment of body composition. Appl Physiol Nutr Metab. 2013; 38(1): 27-32. doi:10.1139/apnm2012-0129.

20. Kim M, Kim H. Accuracy of segmental multi-frequency bioelectrical impedance analysis for assessing whole-body and appendicular fat mass and lean soft tissue mass in frail women aged 75 years and older. Eur J Clin Nutr. 2013; 67(4): 395-400. doi:10.1038/ejcn.2013.9.

21. Haapala I, Hirvonen A, Niskanen L, et al. Anthropometry, bioelectrical impedance and dual-energy X-ray absorptiometry in the assessment of body composition in elderly Finnish women. Clin Physiol Funct Imaging. 2002; 22(6): 383-391.

22. Newman AB, Kupelian V, Visser M, et al. Strength, but not muscle mass, is associated with mortality in the health, aging and body composition study cohort. J Gerontol A Biol Sci Med Sci. 2006; 61(1): 72-77. 
doi:10.1093/gerona/61.1.72.

23. Burger HG, Hale GE, Robertson DM, Dennerstein L. A review of hormonal changes during the menopausal transition: Focus on findings from the Melbourne Women's Midlife Health Project. Hum Reprod Update. 2007; 13(6): 559-565. doi:10.1093/humupd/dmm020.

24. Delmonico, Matthew J. Beck DT. The Current Understanding of Sarcopenia : Emerging Tools and. Am J Lifestyle Med. 2015; XX(X): 1-15. doi: $10.1177 / 1559827615594343$.

25. Bean JF, Kiely DK, Herman S, et al. The relationship between leg power and physical performance in mobility-limited older people. J Am Geriatr Soc. 2002; 50(3): 461-467. doi:10.1046/j.1532-5415.2002.50111.x.

26. Zamboni M, Mazzali G, Zoico E, et al. Health consequences of obesity in the elderly: a review of four unresolved questions. Int J Obes. 2005; 29(9): 10111029. doi:10.1038/sj.ijo.0803005.

27. Roberts HC, Denison HJ, Martin HJ, et al. A review of the measurement of grip strength in clinical and epidemiological studies: Towards a standardised approach. Age Ageing. 2011; 40(4): 423-429. doi:10.1093/ageing/afr051.

28. Fielding RA, Vellas B, Evans WJ, et al. Sarcopenia: An Undiagnosed Condition in Older Adults. Current Consensus Definition: Prevalence, Etiology, and Consequences. International Working Group on Sarcopenia. J Am Med Dir Assoc. 2011; 12: 249-256. doi:10.1016/j.jamda.2011.01.003.

29. Studenski SA, Peters KW, Alley DE, et al. The FNIH sarcopenia project: Rationale, study description, conference recommendations, and final estimates. Journals Gerontol - Ser A Biol Sci Med Sci. 2014; 69 A(5): 547-558. doi:10.1093/gerona/glu010.

30. Studenski SA., Peters KW, Alley DE, et al. The FNIH sarcopenia project: Rationale, study description, conference recommendations, and final estimates. Journals Gerontol - Ser A Biol Sci Med Sci. 2014; 69 A(5): 547-558. doi:10.1093/gerona/glu010.

31. Studenski S, Perera S, Patel K. Gait Speed and Survival in Older Adults. Jama. 2011; 305(1): 50-58. doi:10.1001/jama.2010.1923.Gait.

32. Alley DE, Shardell MD, Peters KW, et al. Grip strength cutpoints for the identification of clinically relevant weakness. Journals Gerontol - Ser A Biol Sci Med Sci. 2014; 69 A(5): 559-566. doi:10.1093/gerona/glu011.

33. McLean RR, Kiel DP. Developing Consensus Criteria for Sarcopenia: An 
Update. J Bone Miner Res. 2014; 69(5): 576-583.doi:10.1002/jbmr.2492.

34. Heymsfield SB, Adamek M, Gonzalez MC, Jia G, Thomas DM. Assessing skeletal muscle mass: Historical overview and state of the art. J Cachexia Sarcopenia Muscle. 2014; 5(1): 9-18. doi:10.1007/s13539-014-0130-5.

35. Heyward, Vivian, Wagner D. Body Composition Reference Methods. In: Applied Body Composition Assessment.; 2004: 40-45.

36. Delmonico MJ, Kostek MC, Johns J, Hurley BF, Conway JM. Can dual energy $\mathrm{X}$-ray absorptiometry provide a valid assessment of changes in thigh muscle mass with strength training in older adults? Eur J Clin Nutr. 2008; 62(12): 1372-1378. doi:10.1038/sj.ejen.1602880.

37. Chen Z, Wang Z, Lohman T, et al. Dual-energy X-ray absorptiometry is a valid tool for assessing skeletal muscle mass in older women. $J$ Nutr. 2007; 137(12): 2775-2780.

38. Heyward, Vivian, Wagner D. Bioelectrical Impedance Analysis Method. In: Applied Body Composition Assessment.; 2004: 87-97.

39. Heymsfield SB, Wang Z, Baumgartner RN, Ross R. Human body composition: advances in models and methods. Annu Rev Nutr. 1997; 17: 527-558. doi:10.1146/annurev.nutr.17.1.527.

40. Ziai S, Coriati A, Chabot K, Mailhot M, Richter MV., Rabasa-Lhoret R. Agreement of bioelectric impedance analysis and dual-energy X-ray absorptiometry for body composition evaluation in adults with cystic fibrosis. $J$ Cyst Fibros. 2014; 13(5): 585-588. doi:10.1016/j.jcf.2014.01.006.

41. Heymsfield SB, Smith R, Aulet M, et al. Appendicular skeletal muscle mass: Measurement by dual-photon absorptiometry. Am J Clin Nutr. 1990; 52(2): 214-218.

42. Kyle UG, Genton L, Hans D, Pichard C. Validation of a bioelectrical impedance analysis equation to predict appendicular skeletal muscle mass (ASMM). Clin Nutr. 2003; 22(6): 537-543. doi:10.1016/S0261-5614(03)000487.

43. Tengvall M, Ellegård L, Malmros V, Bosaeus N, Lissner L, Bosaeus I. Body composition in the elderly: Reference values and bioelectrical impedance spectroscopy to predict total body skeletal muscle mass. Clin Nutr. 2009; 28(1): 52-58. doi:10.1016/j.clnu.2008.10.005.

44. Bosaeus I, Wilcox G, Rothenberg E, Strauss BJ. Skeletal muscle mass in hospitalized elderly patients: Comparison of measurements by single-frequency 
BIA and DXA. Clin Nutr. 2013: 1-6. doi:10.1016/j.clnu.2013.06.007.

45. Kim M, Shinkai S, Murayama H, Mori S. Comparison of segmental multifrequency bioelectrical impedance analysis with dual-energy X-ray absorptiometry for the assessment of body composition in a communitydwelling older population. Geriatr Gerontol Int. 2015; 15: 1013-1022. doi:10.1111/ggi.12384. 


\section{Appendix B. Phone Screen Assessment}

URI Resistance Exercise Study to Reclaim Lean Muscle and Strength (URI RESTORE ME Project)

Data Sheet for Detailed Subject Telephone Interview

\section{$\square$ Brief Explanation of Study \\ $\square$ Permission to Conduct Interview?}

Yes No

How did you hear about the study (if not already recorded)?

Name: Dr./Ms./Mrs.

Address:

Phone \#:

E-Mail:

Best Way and Time to Contact:

- Time Commitment - Available - Include 7-9am or 3-5pm MWF preference Yes __ No Wants to be contacted after (Date)

Comment:

- Proximity to URI

Length of commute:

Within reasonable commute miles or minutes commute

Too far to commute

- Age

Age: yrs

Date of Birth:

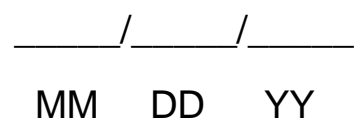


Approximate Height:

Approximate Weight:

BMI:

- Race

American Indian or Alaskan Native

Asian or Pacific Islander

Black, not of Hispanic origin

Hispanic

White, not of Hispanic origin

Other/Unknown

- Highest level of education completed

Less than high school

High school or GED

Some college

Two-year college degree (e.g. Associates)

Four-year college degree (e.g. B.S., B.A.)

Masters degree

Doctoral degree

Professional degree (e.g. M.D., J.D.)

Other (please specify)

- Have you attained menopause? Yes

No

If Yes, for how long?

- Smoking

Always Non-Smoker

Non-Smoker for Smoker

- Physical Activity

Participates in regular ( $>1 \mathrm{x} / \mathrm{wk}$ for past 3 months) exercise? Yes No

If yes, describe in detail (e.g. frequency, intensity, duration, mode) 
Describe other non-structured physical activity (e.g. leisure time, gardening, occupational, or other)

- Cardiovascular (heart, blood, or blood vessel) conditions?

No Yes (Record on Medical History/Treatment Form)

Comments:

- Respiratory Conditions?

No Y_ Yes (Record on Medical History/Treatment Form)

Comments:

- Osteoarthritis/Degenerative Arthritis

No Yes

If yes, how long and what was the severity

- High Blood Pressure

No

Yes__ Controlled (Record High BP and Treatment on Medical History/Treatment Form)

Yes Uncontrolled

Comments:

- Orthopedic conditions (knee, neck, or other back pain)

No Yes

If yes, describe in detail including severity 
- Diabetes

No

Yes - Type 2. If type 2, taking insulin now?

Yes - Type 1 (Insulin Dependent)

Comments:

- Any major surgeries as an adult?

No _ Yes

If yes, what type (e.g. surgeries of the joints, heart surgeries, angioplasty, bypass surgery, pacemakers, etc.) and date(s)

- Other Medical Conditions (especially those that would make exercise difficult or unsafe)

No

Yes (Record on Medical History/Treatment Form)

Comments:

- Medication Info - See last page

No

Yes (Record on Medical History/Treatment Form)

Comments: 
- Personal Physician Info

Name of Physician:

Specialty of Physician:

Phone Number:

Fax Number:

Address (if phone and fax unknown):

\section{- Summary}

Interviewer Printed Name:

Interviewer Signature:

Questions/Comments:

Reviewer Initials:

Appears to Qualify

Need More Information

Needs Drs. Delmonico, Hatfield, Xu, or Lofgren to review Not Qualified

Questions/Comments: 


\section{Appendix C. Consent Form for Research}

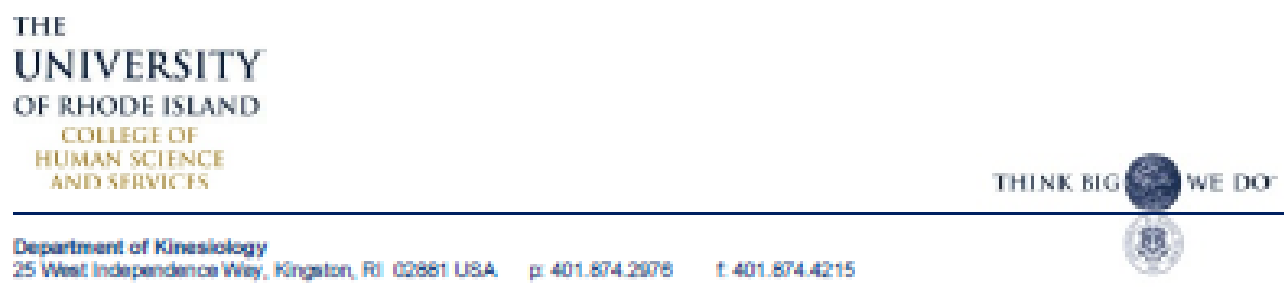

\section{CONSENT FORM FOR RESEARCH}

Title of Project: Effects of a Resistance Training Program in Older Women with Sarcopenia

You are invited to take part in a research project described below. The researchers will explain the project to you in detail. You should feel free to ask questions. If you have more questions later, Drs. Matthew Delmonico (Phone: 401-874-5440) and Ingrid Lofgren (401-8745706) from the Departments of Kinesiology and Nutrition and Food Sciences at the University of Rhode Island (URI), the persons mainly responsible for this study, will discuss them with you. The general eligibility criteria for inclusion to this study include having/being 1) a woman with low physical function and/or low lean mass, 2) age 65-84 years, 3) no recent medication changes, 4) post-menopausal, 5) the ability to speak and read English, 6) a body mass index of $18.5-45.0 \mathrm{~kg} / \mathrm{m}^{2}$ and 6) free of diseases or conditions that would prevent reasonably safe participation in an exercise program.

\section{Description of the project:}

You understand that the primary purpose of this study is to assess the role that a 12-week resistance exercise training program plays in inproving muscle mass, physical functioning, and sarcopenia (the age-related loss of muscle mass) classification factors. Resistance training is has been shown to be effective for improving health outcomes in older women, including physical functioning but has not been tested in women who have been identified by new guidelines as having low muscle mass and physical functioning. Another purpose of the study will be to assess the influence resistance training on changes in bone density, blood pressure, muscle function, health indicators, blood lipids (fats) and sugar, fat and protein metabolism. Your participation time will vary depending on which group to which you are randomized and can range from 3-4 hours per week. All of the testing and intervention sessions will take place on the URI Kingston campus (Independence Square building, and you are responsible for your own transportation to all of the testing and intervention sessions).

\section{What will be done:}

You understand that if you choose to participate, the study potentially requires your involvement in five phases.

PHASE 1: During Phase 1, you will undergo a screening visit to determine if you meet the criteria for sarcopenia which include low muscle mass and either 1) slow normal walking speed or 2) low grip strength. The muscle mass test simply requires you to stand barefoot on a device with metal conducting pads while holding onto another set of conducting pads with

Initial Date Page 1 of 6
THI

UNIVERSITY Ia: HU1619-16s

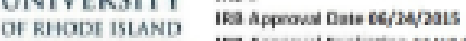

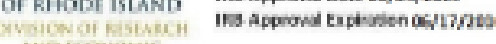


your hands. This will tell us in less than one minute bow much arm and leg muscle you have. This device uses a very low electrical current in order to estimate muscle and fat mass on your body. This test only takes about one minute to complete but is a valid and reliable measure of body composition with very few risks. The walking test simply requires you to walk four meters (about 15 feet) at your normal walking pace. The hand grip strength test only takes a couple of minutes and you will be asked to squeeze a device two times with both hands (separately) as hard as you can. Your beight and weight will also be measured at this visit. If you meet the criteria that identify you as having sarcopenia, then you will be invited to take part in the project. If you do not meet these criteria, we will provide you with information about your muscle mass and physical functioning, along with information about how you can maintain or improve these bealth aspects on your own.

PHASE 2: If you are identified as having sarcopenia, then you will be invited to take part in the research trial. Preliminary testing (four visits of $\sim 1-1.5$ bours per visit) will be necessary. In addition to a repeat of some of the measures in Phase 1 , your, waist and hip girths will be measured and you will be asked to complete some tasks to measure your ability to carry out normal daily activities at the Independence Square building. These tasks include a usual pace 400 meter ( $\sim 1 / 4$ mile) walk, rising from a chair, standing balance tests, and short walks. Any risk of injury during the conpletion of these tasks will be minimized by having all sessions supervised by an exercise physiologist qualified to direct this type of testing. In addition, you will be asked to complete several health questionnaires. These include sleep quality, general bealth, food intake, a dietary screening tool, a balance survey, and pbysical activity habits.

You understand that your percent body fat and bone density will be performed using dual energy x-ray absorptiometry (DXA) located in room 129 of the Independence Square building. This will require you to lay on a table a wearing bospital scrubs for about 20 minutes for the entire procedure. A licensed radiology technician will perform the DXA scans. There is no cost to you or your insurance for these scans.

The flexibility of your leg muscles will be tested by using a simple test that requires you to attempt to touch your toes while seated. You also understand that strength assessments will be performed on machines or devices that measure how much force and how fast you can exert force through a typical range of leg, back, chest and knee extension motion. Leg strength testing will be performed by measuring the maximal amount of force that you can move through the full range of an exercise. You may experience some temporary muscle soreness as a result of the testing sessions. There is also a risk of muscle soreness or skeletal injury from strength and testing as well as from the exercise training. The investigators of this study will use procedures designed to minimize this risk.

A blood test will be done that will include two blood draws to analyze blood sugar, lipids (fats), and other blood proteins. You understand that there is a risk of bruising, pain, and in rare cases, infection or fainting as a result of blood sampling. However, these risks to you will be minimized by allowing only qualified people to draw your blood. Your blood pressure will also be assessed during this first phase.

TIII

UNIVERSITY

OF RHODI ISLAND

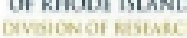

Ins E Hutals-10s

Fa Appovod Date C6/24/2ats

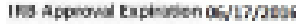


At the end of the Phase 2 (testing), you will be randomly assigned (like a flip of a coin) to either a resistance training group or a general physical activity group for Phase 3 . You understand that you are not allowed to choose which group you will be assigned.

PHASE 3: INIERVENTION

Resistance Training Sessions (Resistance Training Group)

If you are randomized to the resistance training exercise group, you will also be asked to participate in three (3) supervised exercise sessions per week ( $\sim 45$ minutes per visit) for the 12-week intervention in the Independence Square building, room 190. During each resistance training session you will be asked to exercise on machines or free weights that offer resistance against extending and flexing your arms, legs, and trunk region. All sessions will start with a resting blood pressure and a brief warm-up. The first several resistance training sessions will begin with lighter resistances to get you used to the resistance training program. The resistances will be gradually increased based on individual progress. The resistance will always be adjusted so that you are exercising at near maximal effort. You will be able to provide feedback using standardized pain and discomfort rating scales. Your overall progress will be monitored by an exercise specialist so that you are able to tolerate the exercise. Each session will end with a cool-down and a final blood pressure measurement. No special clothing is required, but you should dress in clothing that is comfortable and that allows you to move freely. You will also be instructed to stop exercising immediately if you experience chest pain, muscle injuries, or any other unexpected symptoms. Although you will always have supervision when doing exercise training during this study, if you ever experience chest pain while exercising at other times, you should immediately call 911 to seek emergency care and notify your primary care physician. If you have any problems or injuries, you should also notify a member of the study team. Study team members and their phone numbers are noted on the first page of this consent form.

\section{Genemal Phasical Activity Sessions (Active Control Group)}

If you are assigned to the active control group, you will also be asked to participate in three (3) supervised exercise sessions per week ( $\sim 5$ minutes per visit) for the 12-week intervention in the Independence Square building, room 190. During each general physical activity session, you will engage in individual and group exercise sessions to increase your overall weekly physical activity. Activity sessions will vary but will include activities recommended by the American College of Sports Medicine for adults 65 years and older. Some of these activities may include walking, Tai Chi, light calisthenics, and stretching. All sessions will start with a resting blood pressure and a brief warn-up. The first several exercise sessions will begin with very light activities to get you used to the training program. The difficulty of the exercises will be gradually increased based on individual progress. You will be able to provide feedback using standardized pain and discomfort rating scales. Your overall progress will be monitored by an exercise specialist so that you are able to tolerate the exercise. Each session will end with a cool-down and a final blood pressure measurement. No special clothing is required, but you should dress in clothing that is comfortable and that allows you to move freely. You will also be instructed to stop exercising immediately if you experience chest pain, muscle injuries, or any other unexpected symptoms. Although you will always have supervision when doing

Initis. Date Page 3 of 6
TIIT

UNIVERSITY ins mU1As-10s

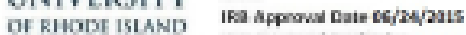

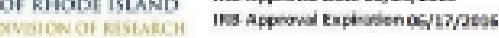


exercise training during this study, if you ever experience chest pain while exercising at other times, you should immediately call 911 to seek emergency care and notify your primary care physician. If you have any problems or injuries, you should also notify a member of the study team. Study team members and their phone numbers are noted on the first page of this consent form.

PHASE 4: Phase 4 will be a repeat of previously taken measures at the mid-point (week 6 ) and at the end (after week 12) of the 12-week exercise intervention.

PHASE 5: Phase 5 (the final phase) of the project will be six month follow-up testing session after Phase 4. You do not need to do any special activity or diet during this period.

\section{Risks or discomfort:}

You understand that it is possible that heart or blood vessel problems could arise during your participation in the testing or training involved in this study. Although highly unusual, it is possible that these problems could lead to a beart attack, stroke or even death. Therefore, prior evaluation and written clearance with a signature from your personal physician is strongly encouraged for you to participate in this study. You also understand that it is possible that these risks will not be eliminated completely, even with a medical evaluation prior to participation in the study. However, the investigators believe the risk of harm from study participation is relatively small and that the benefits of the study will likely outweigh any potential risks. Additionally, you understand that with the testing described above, resistance training and exercise in general there is a risk of muscle soreness or other muscle injury as well as skeletal injury. Because exercise in this study does require some degree of balance, there is also a risk of falling associated with exercise. However, the investigators will take precautions in order to reduce the likelihood that these adverse events will occur.

You understand that there will also be a very low total radiation dose for the DXA scans $(\sim 39$ millirem), which is about one-fifth the radiation dose of a standard chest X-ray and is well below the maximal annual radiation dose ( 5 rems) allowed for exposure in the workplace. Naturally occurring radiation (cosmic radiation, radon gas, etc.) gives each person a whole body radiation dose of about 300 millirems per year. Therefore, the total dose of radiation exposure due to DXA is considered low. The major risk from high radiation exposure is passing on damaged genes (genetic mutations) to offspring. Therefore, this risk is of primarily a concern for those who are of childbearing age.

In case there is any injwy to the subject:

In the event of physical injury resulting from participation in this study, upon your consent, emergency treatment will be available at South County Hospital with the understanding that any injury that required medical attention becomes your financial responsibility. You understand that URI will not provide any medical or hospitalization insurance coverage for participants in this research study, nor will they provide compensation for any injury sustained as a result of this research study, except as required by law.

You understand that if you are injured while participating in this research project as a result of negligence of all state employees who are involved in this research project, you may be able to be compensated for your injuries in accordance with the requirements of the Federal

Initisl Dato Page 4 of 6

TII

UNIVERSITY IG: HU145-105 OF RHODI ISLAND IFa Appowas Dats 66/24/2ats

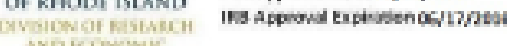


Tort Claims Act. If you are a federal employee acting within the scope of your employment, you may be entitled to benefits in accordance with the Federal Enployees Compensation Act.

Confidentiality:

All information collected in this study is confidential, and your name will not be identified and linked to any electronic study data at any time to anyone other than the principal investigators of the study. Your data will be coded with an $\mathrm{D}$ number only, which will be linked back to you only by the principal investigators of the study. Your part in this study is confidential within legal limits. The researchers and the University of Rhode Island will protect your privacy, unless they are required by law to report information to city, state or federal authorities, or to give information to a court of law. Otherwise, none of the information will identify you by name. All study data, including this consent form, will be locked in a file cabinet and also stored in a study computer with a password secured in our study office (Independence Square building, Suite P, room 119).

Benefits of this study:

You understand that this study is not designed to help you personally, but may help the investigators better understand which interventions are the most effective in helping women who have sarcopenia improve their muscle mass and physical function. However, because of what is already known regarding the effects of resistance training and exercise in general, it is likely that you will notice some benefits. These potential benefits include inproved strength, mobility and blood pressure.

For your participation in the study and after the study is completed, you will receive, free of charge, information about your blood pressure, blood test results, body conposition, muscle strength, and physical function.

\section{Decision to quit at any time.}

You understand that is your decision and your decision alone whether or not you consent to participate in this study. You are free to ask questions about this study before you decide whether or not to consent to participate in it. Also, if you consent to participate in the study you are free to withdraw from participation at any time without penalty or coercion, or without any requirement that you provide an explanation to anyone of your decision to withdraw. You or your insurance company will not be charged for the classes or training sessions.

\section{Rights and Complaints:}

If you are not satisfied with the way this study is performed, you may discuss your complaints with the principal investigators, Drs. Matthew Delmonico at (401) 874-5440, Disa Hattield at (401) 874-5183, Ingrid Lofgren at (401) 874-5869, or Furong Xn (401) 874-2412 (anonymously, if you choose). In addition, if this study causes you any injury or if you have questions about your rights as a research subject you may contact the office of the Vice President for the Division of Research and Economic Development, Carlotti Administration Building, 2nd Floor, 75 Lower College Road, Suite 2, University of Rhode Island, Kingston, Rhode Island; telephone: (401) 874-4576.

Altematives to study participation: If you choose not to participate in this study, you are encouraged to discuss with your physician about exercise strategies.

Initial__ Date___ Page 5 of 6
Tur

UNIVERSITY IBas HU141s-10s

OF RHODI ISLAND IFa Appowas Date C6/2Mats

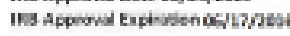


You have read and understand the above information in the Consent Form and have been given adequate opportunity to ask the investigators any questions you have about the study. Your questions, if any, have been answered by the investigators to your satisfaction. Your signature on this form means that you understand the information and you agree to voluntarily participate in this study.

Siguature of Participant $\quad$ Signature of Researcber

Typed/printed Name

Typed/printed name

Date

Date

By signing again below you give permission for the investigators to store and use your blood samples for future research only related to the study objectives.

Signature of Participant $\quad$ Signature of Researcber

Typed/printed Name

Typed/printed name

Date

Date

Please sign both consent forms, keeping one for you.

Initial___ Date___ Page 6 of 6

TII

UNIVERSITY 193: HU1215-108

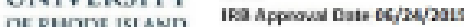

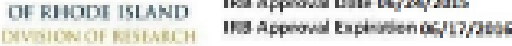

Axs kcowose

DFMLOFisT 


\section{Appendix D. Medical History}

36 Chapw 2 Tesirg Conocpts

\section{$\mathbb{R}$ physical fitness activity 2.2}

\section{Medical/Health Ouestionnaire}

Acording to the American College of Spoets Medidine, a medical examination and dinical eswrcise test ls roocenarended prioe to (1) modenate or vigoevus ecercise training fee theee at high ribk for disease, and (2) viganous esoencise tralning for moderaterisk individuals. The ACSM rocommends that the poutast modical history be thorough.

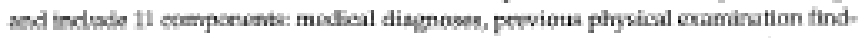

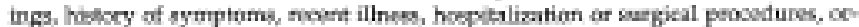
thopedic problems, mediuaticen ase and drug allergies, lisesty le hubita, eweciev history. work history, and fomily history of disease. The following medical and halth quasSonnaire meets these crterta and can be used so gain a useful history on diers at Einvss-testing focilities kocaided in woeksitus, hoopitab, and unirersities In this activitg solext a faculty member or arember of the carmunuity that you foel would benefit from this process. Have the person aresere the questicels in the medical questionaire, and then summarize important findings in the following blanks.

1. Symptoms of signs of diwease

2 Chronic disoase rik factors

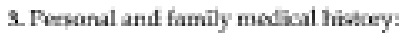

4. Medicatices:

5. Summary of Restyle habits: 


\section{MedicallHealth Questionmaire}

Pernanel finformatiou

\begin{tabular}{|c|c|c|c|c|c|c|c|c|c|}
\hline \multicolumn{10}{|l|}{ Today's dast } \\
\hline How obld are you? & - & - ye: & & & & & $\operatorname{Sex} 5$ & Male; & O Female \\
\hline \multicolumn{10}{|c|}{ Plevse circle the bighest grade in sctwool you have completed: } \\
\hline Elotseniary school & 1 & 2 & 3 & 4 & $\mathbf{5}$ & 6 & 7 & 8 & \\
\hline High school & 9 & 10 & 11 & 12 & & & & & \\
\hline College/Postgrad & 13 & 16 & 15 & 16 & 17 & 18 & 19 & $20+$ & \\
\hline
\end{tabular}

What is your marital status? a Single; a Married; a Widowed; a Dworoed/Separated Facte ur ethenc backignound:

\begin{tabular}{|c|c|c|}
\hline Whise, not of Hisportic origin & a American Indian/Alaskan native & a Asan \\
\hline Q Black, not of Hispanic origin & O Pacific Islankier & Uispverix \\
\hline \multicolumn{3}{|c|}{ 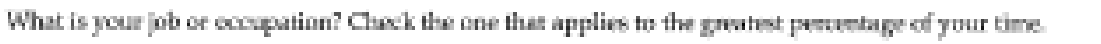 } \\
\hline Health profiessional & a Disabled, unable to work & Service \\
\hline a Masager, educatoe, prodessional & O Operaboe, fateicasoe, laboner & D Unmployed \\
\hline a Skilled crafts & q Homemaler & Shodent \\
\hline Jectrical, sales, support & Q Retired & D Other \\
\hline
\end{tabular}

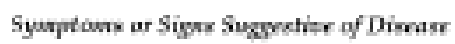

Place a check in the bor. If your answer is "yes"

D. L. Have yos experienced unesal pain or discomfort in your chest, reck, jow, anms, or other areas that may be due to hoart problems?

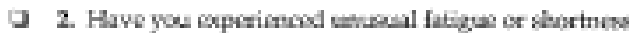
of beovith at nest, during usual activities, or dering mild-6r-moderate exereise (e.5, elimbing otain rarying gnoceries, brisk walking, goling/?

3. Have you had any peoblems with dizziness of fainting?

D. Do you suffer from swelling of the ankiles fankle edemal?

C. Hawe you experienord an umuasal and repid throbbing or fluttering of the heart?

a 7. Have you experienced sevese pain in your log muscles during walking?

D. B. Has a docior told you that you have s herot murmur?

a 4. When you stand sw, or sometimes during the right while you are slceping, do you have difficulty bresthing?

Ctenuic Dimase Risk Factors

Place a check in the box if your znewer is "yea"

D. Avo yoca a male oner age es yoars, or a fumale ower upi 55 years, or a femsie who has experienosd premstume mencpouse and is nok on estrogen replacement therogy?

10. Has your father er boother lad a hoart attack ox died saddenly of hurt clicwuse before age 55 yours. has your mother or sister evperienced these heert problems before age 65 rears?

D 11. Are you a carnent cigancthe smolver?

D 12. Has a doctor fold you that you hove bigh blood prossure imore than 140/90 mm Hlgil, or ane you on medication to control your blood pocssure?

0 13. Is your total serum thalesirol greaber thin $210 \mathrm{mg} / \mathrm{dl}, \mathrm{cor}$ has a doctor bold you that your cholesterol is at a high-risk bevel?

a 14. Do you huve diabetes mellitus?

a 15. Are you physically inactive and sedentary (little physical activity an the job of during keisure time??

a 16. Dexing the past yes, world you cay that yos experienod exough atres, strain, and presouce to hwre a significant effect on your health?

17. Do you eat foods nearly every day that ase hight is fat and chobestord such as fatty matx, choven, fried foods, butsot, whale milk, on vegs?

a 18. Do you tend so wroid foods that are high in fiber such as whole-grain breads and cereak, fessh trults, oe vegetables?

D 19. Do you weigh 30 or mune poundes mane than you shoukd?

D 20. Do you average moee than two alcolholic drinks each day? 


\begin{tabular}{|c|c|c|}
\hline \multicolumn{3}{|c|}{ Modinal Hisfory } \\
\hline \multicolumn{3}{|c|}{ 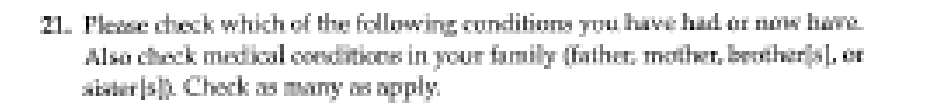 } \\
\hline Personal & Family & Medieal Condition \\
\hline a & $\square$ & Coconary bast disease, heart wtick, oconary artery ourgery \\
\hline a & $\square$ & Argeina \\
\hline $\mathbf{0}$ & 9 & High blood peessure \\
\hline D & ם & Peipheral vasoular dicoese \\
\hline D & $\square$ & Phicbitis or emboli \\
\hline ט & 0 & Other heart pmblems (specify: \\
\hline 口 & $\square$ & Larg canour \\
\hline a & $\mathbf{0}$ & Brewat cancer \\
\hline a & o & Pvorate cancer \\
\hline a & D & Colorectal cancer fbomel conoer) \\
\hline u & D & Skin canost \\
\hline 9 & D & Other cancer Gspecify: \\
\hline a & 0 & Stroke \\
\hline ב & D & Chrceic obstruetive pulmotury disenee (emphysema) \\
\hline a & a & Prncumonis \\
\hline 山 & a & Avithma \\
\hline a & 口 & Bronchitis \\
\hline$\square$ & Q & Diabetes molitus \\
\hline a & 口 & Thyroid problems \\
\hline 0 & 0 & Kidney disease \\
\hline 口 & ロ & Liver disonse fcirrtasis of the liver? \\
\hline ב & ב & Hepatitis \\
\hline 口 & ] & Gallsbones/guilaladder disease \\
\hline 口 & 口 & Ostuponceis \\
\hline c & $\square$ & Arthritis \\
\hline ב & $\square$ & Gerut \\
\hline$a$ & $\square$ & Anemia (low inon) \\
\hline$\square$ & a & Bore fractume \\
\hline 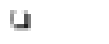 & 口 & Mavior irviury to foot, lege kene, bip, os shrabler \\
\hline a & $\square$ & Major infury to back ce neck \\
\hline 口 & ] & Shomoch/duodemal vioer \\
\hline 9 & 9 & Kectal growth or bleeding \\
\hline D & a & Cataracts \\
\hline$\square$ & $\square$ & Glavooums \\
\hline 0 & a & Hearing loss \\
\hline 口 & a & Depresodion \\
\hline Q & 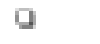 & High anoiety, phobias \\
\hline 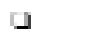 & $\square$ & 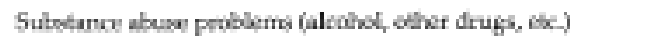 \\
\hline a & $\square$ & Esting discoders (anonevia, bulimia) \\
\hline 0 & व & Problems with menstruation \\
\hline
\end{tabular}




\begin{tabular}{|c|c|c|}
\hline $\boldsymbol{D}$ & g & Hystemetany \\
\hline$\square$ & ב & Sheping problems \\
\hline Q & $\square$ & Allergiks \\
\hline$\square$ & ב & $\begin{array}{l}\text { Any cther health problems (plesese opecify, and include } \\
\text { infurmation on any recent illnesses, hospitalizatices, oc } \\
\text { sungical prosedures); }\end{array}$ \\
\hline
\end{tabular}

22. Plesec check any of the following medications you cuerently take regularly. Also give the name of the medicatioe.

\section{Medication}

a Heart midigine

D Blood poessure medidine

] Blocd divelosherel medicine

[. Hoemanes

(U) Burth coestrul pills.

a Medicine for bresthing/lungs

Insulin

] Otwer molicite for diabuges

a Arthritis muaticine

a Modicine for doponsedion

a Medicine for mosiety

a Thyoid medicine

a Medicine for ulcers

] Pnirbiller medicine

] Allergr medscine

口 Other (plesse specify)

\section{Name of Medicatioe}
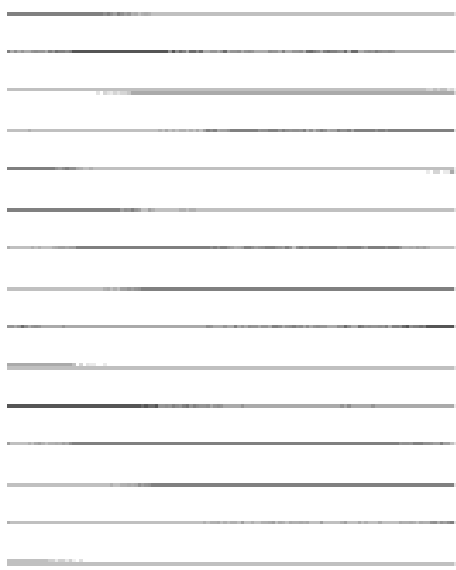

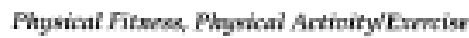

23. In general, compind to other persons your apk, nate how physically fit yora ane

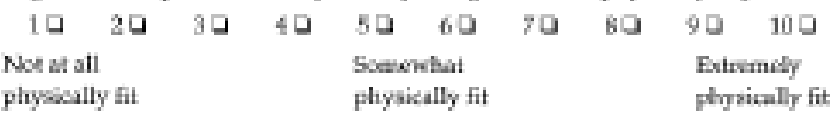

24. Outside of your normal work or daily nespornalbetives, how often do you engago in evercise that at loast modesabely incrnees your beeathing and heaft mes and makes you sweek, fige at leact 20 minutus fouch as brisk walkire, cyckire. swimaning jogying acrobic danow, stair dimbing, nowing, baskethall, nacquetball, vigorows yard workj.

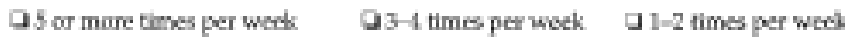
$\square$ Lass than 1 tims por week a boklam or mever

25. How moch band physical woek is required on your job?
a Aroar deal
口A moderate amount
口A litts
Dome

26. How long have you exencised of played sporis regulariy?
DI do tot exercise mpularly
a lews than I year
a 1-2 your
a2-5years
प5-10 yesrs
a More than 10 years. 
Diest

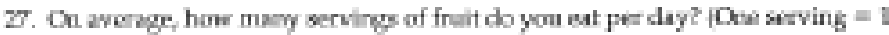
medium apple, benans, cennge, etc; th cup of chopped, ecolked, ce cannin fruit; * cup of truit juice.)
DNes
व1
02
03
D tor more

28. On mreram, how maty sutvinga of veretaliss do you est per day? (One serving -

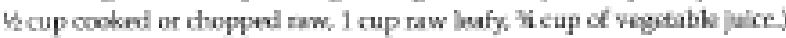
DNane
口i-2
as
प4
ב5 mare

29. On average, how matry servings of bresd, cenesl, rice, or paita do you eat por day? (One serving =1 slioe of bread, 1 ounce of resty-to-eat cereal, Hi cop of cosaked cereal, rice, or pash. ?
a None
D 1-3
- 4-6
a7-9
$\square \mathrm{Do}$ or more

30. When yor pee grain and asenl products, do you emphasixe.

Q Whale grain, bigh fiber $\square$ Mixture of whole grain and nefindd $\square$ Kefined, bsw Elsw-

31. On average, how many servings of red ment (not lean) do you ent per day? (One serving $=2-3$ ounces of steak, noast bet, lamb, poek dops, tam, burgers, etc)
ave
ב1
ㅁ2
प3
D ar more

32 On awerape, how many servinge of foh, poultry, lain tweat, cooked dry beans, peunut butter, oc nuts do you est per dey? 10 ne aervinis $=2-3$ ounces of mat,

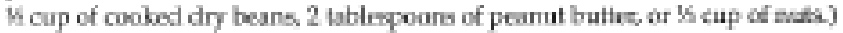
a None
a1
a2
as
D 4 or mone

33. On awerage, hone macy servinge of dairy peoducts do you ent per dar? i One servire - 1 cap of milk or jogurt, 15 chenses of natural chese, 2 ounos of procesed cheses.
D Noee$$
\text { a1 }
$$$$
\text { a2 }
$$$$
\text { D3 }
$$$$
\text { D } 4 \text { or move }
$$

31. When you use dairy products, do pou emphosite
D Regular
Q Low fot
a Nonfat

35. How would you chanacterize your intake of fats and ofls $\{e$. - regular salad dowsing buttor of margarine, mayoreatw, vegetable oilbj?
u High
a Modurate
a Low

\section{Bady Wright}

36. How toll are you (without shoes)? feet inctres

37. How much de you weigh (minimal dodhing and without shoes)? pounds

3R. What is the mest you have ever weighed? pounds

39. Are yow now trying to
a Loes weight
口Gain weight
aStory about the same
a Not trying bo do anythizes:

Prgdiological Health

40. How kave you been freling in general during the past mosth?
$\square$ In excellent spinita
U lin very good spiries
$\square$ In good spirits mostly
a P've bien up and down in qpirits a lot
D In low spirits mostly
G in very low spirits

41. During the past manth, world you say that you experienced stress?
OA bet of
OModerate
a Belatively litik
בAlinost no

62. In the pock yoar, bow awach effors bata stross had an your bealth?
DA lot
D Scere
DHatlly any of cone

43. On merage hour many hours of sleep do yos get in a 24-honar poriod?
D Less than 5
a $5-6.9$
Q7 -9
a Mone than 9 


\section{Sabstance Use}

44. Have you savkend at hast 109 cigarettes in your cntire life? a Yes $0 \mathrm{No}$

45. How would you describe your cigarette imaking habits?

D Nivres smokerd

u Used to smoke

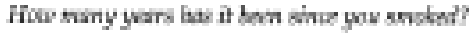
Fass a Still amokse

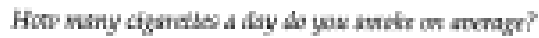
cinseltesiliny

46. Hens many alcoholic drinks do you consume? (A "drink" is a glass od wine, a wise cooler, a botth/can of beer, a shot plins of Bquor, or a mived drick.)
ONever as alcohol
- less thun 1 per wrek
1-6 per week
1 port day
- 2-3 per doy
$\square$ More than 3 por day

Ocoupationel Heicle

47. Pluse describe your main job duties.

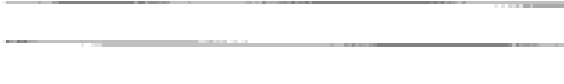

48. Afoer a day's wark, da youra oftem tave pain $\propto$ stiffines that lasts for mone than 3 hours?

49. How often does your woek esalil repotitive pushing. and pulling movements of lifting while bending or twisting, lewding to back pain?

$\begin{array}{llll}\text { All of } & \text { Mast of } & \text { Some of } & \text { Rardy } \\ \text { the time } & \text { the time } & \text { the time } & \text { of cever } \\ \square & \square & \square & \square \\ \square & \square & \square & 0\end{array}$


Appendix E. Baseline Data Collection Sheet

THE

UNIVERSITY

OF RHODE ISLAND

COLLEGE OF

HUMAN SCIENCE

AND SERVICES

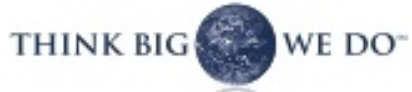

\section{URI RESTORE ME Study Data Sheet}

BaselineTesting Day 1

Participant ID \#: Date:

\begin{tabular}{|c|c|c|}
\hline Measurements & Baseline Testing Day 1 & Initial \\
\hline Resting Heart Rate 1 (bpm) & & \\
\hline Resting Heart Rate 2 (bpm) & & \\
\hline Resting Blood Pressure 1 & & \\
\hline Resting Blood Pressure 2 & & \\
\hline
\end{tabular}

Grip Strength (kilograms)

Dynamometer Setting: $\quad$ Best Grip Trial:

\begin{tabular}{l|l|l|l} 
Grip R1: & Grip R2: & Grip L1: & Grip L2:
\end{tabular}




\section{Baseline Testing Day 1}

\section{Participant ID\#:}

\section{Date:}

\section{SPPB}

\section{A. Side-by-side-stand}

\section{BALANCE SCORING:}

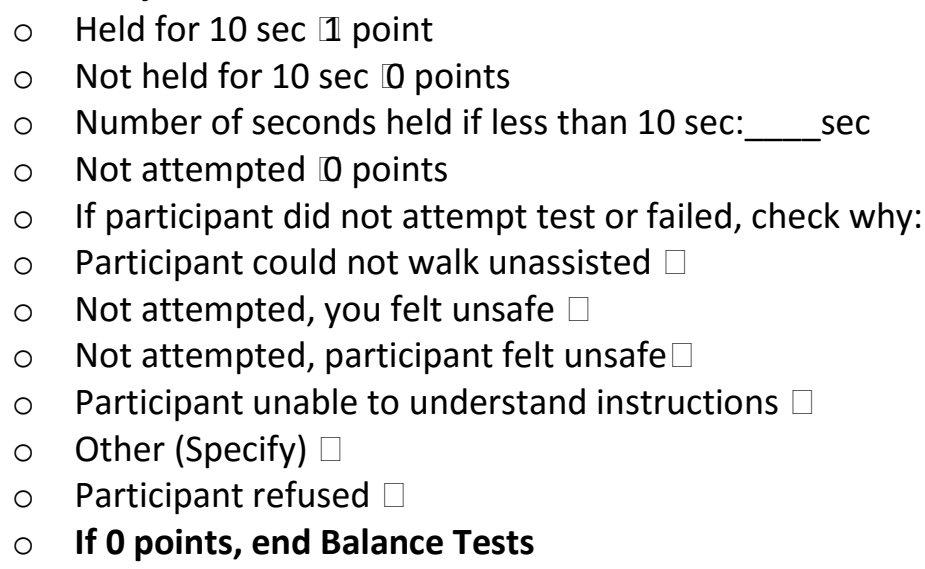

\section{B. Semi-Tandem Stand}

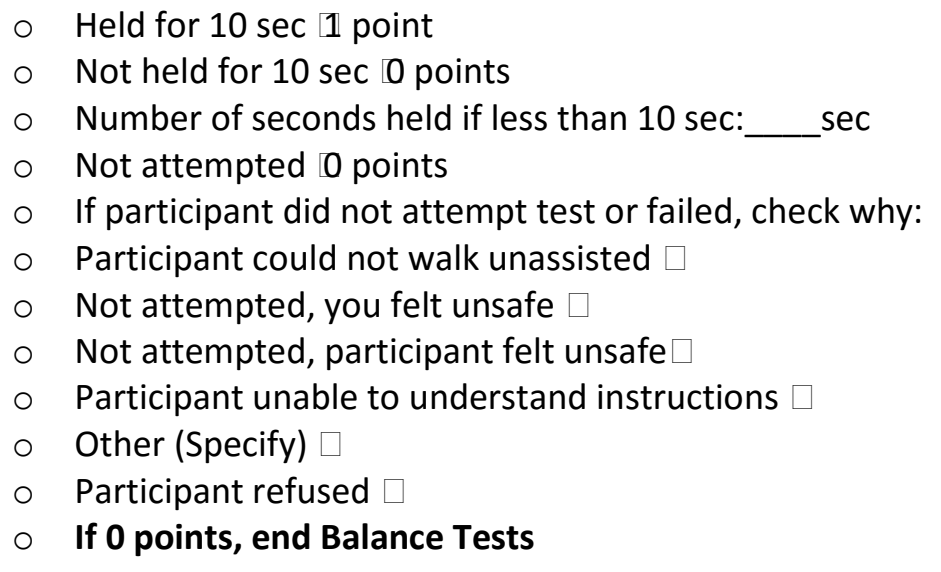

\section{Tandem Stand}

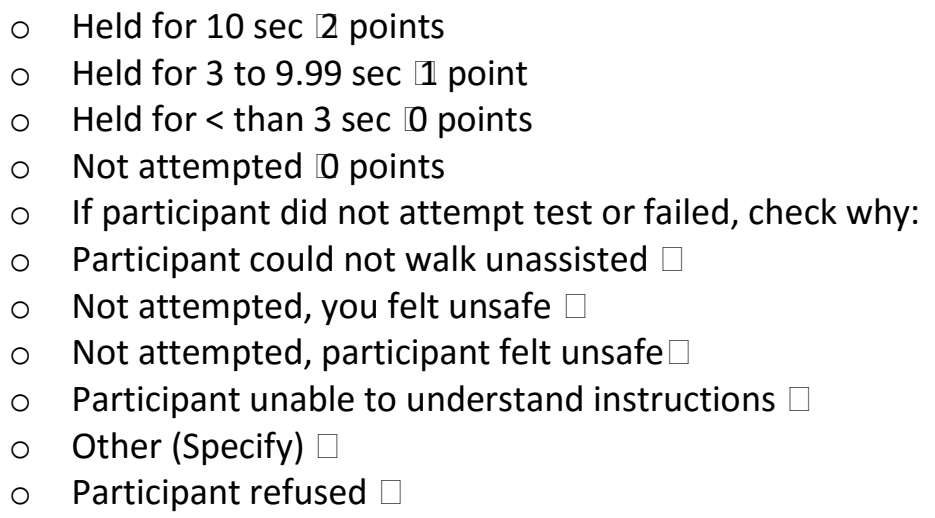

\section{Total Balance Tests score \\ For 4-Meter Walk:}

(sum points)

0 If time is more than 8.70 sec: 1 point 
- If time is 6.21 to $8.70 \mathrm{sec}: \mathbf{2}$ points

O If time is 4.82 to $6.20 \mathrm{sec}: 3$ points

O If time is less than $4.82 \mathrm{sec}: 4$ points

\section{Single Chair Stand Test:}

CHAIR SCORING:

- Safe to stand without help YES $\square$ NO

- Participant stood without using arms YES $\square$ NO $\rightarrow$ If yes go to repeated stand

- Participant used arms to stand YES NO $\rightarrow$ If yes end test; score as 0 points

- Test not completed $\rightarrow$ End test; score as 0 points

- If participant did not attempt test or failed, check why:

- Tried but unable

- Participant could not walk unassisted

- Not attempted, you felt unsafe

- Not attempted, participant felt unsafe $\square$

- Participant unable to understand instructions

- Other (Specify)

- Participant refused

\section{Repeated Chair Stand Test}

○ Safe to stand five times Yes $\square$ No $\rightarrow$ If five stands completed record time

○ Time to complete five stands __sec

- If participant did not attempt test or failed, circle why:

- Tried but unable

○ Participant could not walk unassisted $\square$

- Not attempted, you felt unsafe

- Not attempted, participant felt unsafe $\square$

- Participant unable to understand instructions $\square$

- Other (Specify)

- Participant refused

\section{Scoring the Repeated Chair Test}

0 Participant unable to complete 5 chair stands or completes stands in $>60$ sec: 0 points

- If chair stand time is $16.70 \mathrm{sec}$ or more: 1 points

o If chair stand time is 13.70 to $16.69 \mathrm{sec}$ : 2 points

- If chair stand time is 11.20 to 13.69 sec: 3 points

- If chair stand time is $11.19 \mathrm{sec}$ or less: 4 points

\section{Scoring for Complete Short Physical Performance Battery \\ Total Balance Test score points \\ Gait Speed Test score points \\ Chair Stand Test score ___ points \\ Total Score points (sum of points above)}




\begin{tabular}{|c|c|c|c|}
\hline Test & Result & Date Completed & Initial \\
\hline $\begin{array}{c}\text { 400m walk } \\
\text { (sec) }\end{array}$ & & & \\
\hline SPPB & points scored & & \\
\hline $\begin{array}{c}\text { Single Leg } \\
\text { Stand, 10 sec }\end{array}$ & & & \\
\hline $\begin{array}{c}\text { Sit and Reach } \\
\text { (+/-cm) }\end{array}$ & & & \\
\hline $\begin{array}{c}\text { Timed Up } \\
\text { and Go 1 } \\
\text { (sec) }\end{array}$ & & & \\
\hline $\begin{array}{c}\text { Timed Up } \\
\text { and Go 2 } \\
\text { (sec) }\end{array}$ & & & \\
\hline
\end{tabular}


Baseline Testing

Participant ID \#:

\section{Date:}

\begin{tabular}{|c|c|c|}
\hline Measurements & Date & \\
\hline Resting Heart Rate 1 (bpm) & & \\
\hline Resting Heart Rate 2 (bpm) & & \\
\hline Resting Blood Pressure 1 & & \\
\hline Resting Blood Pressure 2 & & \\
\hline Blood Draw 1 & \\
\hline
\end{tabular}

\begin{tabular}{|c|c|c|c|c|}
\hline Anthropometrics & $\begin{array}{c}\text { Measurement } \\
\text { Measurement }\end{array}$ & Average & Initial \\
\hline Height (inches) & & & & \\
\hline Weight (lbs) & & & & \\
\hline $\begin{array}{c}\text { Waist } \\
\text { Circumference } \\
\text { (inches) }\end{array}$ & & & & \\
\hline $\begin{array}{c}\text { Hip } \\
\text { Circumference } \\
\text { (inches) }\end{array}$ & & & & \\
\hline $\begin{array}{c}\text { BMl (kg/m } \\
\text { (inch }\end{array}$ & & Waist to Hip & & \\
\hline
\end{tabular}

Notes: 
Baseline Testing

Participant ID\#:

\section{Date:}

\begin{tabular}{|c|c|c|}
\hline Measurements & Baseline Testing Day 1 & Initial \\
\hline $\begin{array}{c}\text { Resting Heart Rate 1 } \\
\text { (bpm) }\end{array}$ & & \\
\hline $\begin{array}{c}\text { Resting Heart Rate 2 } \\
\text { (bpm) }\end{array}$ & & \\
\hline $\begin{array}{c}\text { Resting Blood Pressure } \\
\text { 1 }\end{array}$ & & \\
\hline $\begin{array}{c}\text { Resting Blood Pressure } \\
\text { 2 }\end{array}$ & & \\
\hline Blood Draw 2 & & \\
\hline
\end{tabular}

\begin{tabular}{|l|l|l|l|}
\hline & Results collected & Date & Initial \\
\hline DEXA & & & \\
\hline & & & \\
\hline
\end{tabular}

\begin{tabular}{|c|c|c|c|}
\hline \multicolumn{2}{|c|}{ In-Body: BIA } & \multicolumn{2}{|l|}{ Date: } \\
\hline \multicolumn{2}{|c|}{ Voided Bladder } & Yes & No \\
\hline Height: & Weight: & \multicolumn{2}{|l|}{ BMI: } \\
\hline \multirow[t]{2}{*}{ R Arm LM: } & L Arm LM: & R Leg LM: & L Leg LM: \\
\hline & & \multicolumn{2}{|l|}{ Total ALM: } \\
\hline
\end{tabular}




\section{Appendix F. Yale Physical Activity Survey}

\section{YALE PHYSICAL ACTIVITY SCALE}

Interviewer: I wil ask you about some common types of physical activities. Please tell me if you did them during a typical week in the last month. Our interest is learning about the types of physical activities that are a part of your regular work and leisure routines.

For each activity you did, please tell me how many hours you spent doing the activity during a typical week.

Work: (Number of hours per week)

1. Shopping (e.g., grocery, clothes)

2. ___ Stair climbing while carrying a load

3. ___ Laundry (time loading, unloading, hanging, folding only)

4. L__ Light housework: tidying, dusting, sweeping; collecting trash in home; polishing; indoor gardening: ironing

1. __ Heavy housework: vacuuming. mopping; scrubbing floors and walls; moving furniture, boxes, or garbage cans

6. Food preparation (10+ minutes in duration): chopping. stirring, moving about to get food items, pans

7. ___ Food service $(10+$ minutes in duration) setting table; carrying food; serving food

8. _ Dish washing $(10+$ minutes in duration): clearing table; washing/drying dishes, putting dishes away

9. _L_ Light home repair: small appliance repair; light home maintenance/repair

10. __ Heavy home repair: painting, carpentry, washing/polishing car

11. Other:

Yard work: (Number of hours per week)

12.___ Gardening: planting, weeding, digging, hoeing

13. Lawn mowing (walking only)

14.___ Clearing walks/driveway: sweeping, shoveling, raking

15. Other: 


\section{Caretaking: (Number of hours per week)}

16. Older or disabled person (lifting, pushing wheelchair)

17. Childcare (lifting, carrying. pushing stroller)

Exercise: (Number of hours per week)

18. Brisk walking $(10+$ minutes in duration)

19. ___ Pool exercise, stretching. yoga

20. ___ Vigorous calisthenics, aerobics

21. ___ Cycling. exercycle

22. ___ Swimming (laps only)

23. __ Other:

Recreational Activities: (Number of hours per week)

24. Leisurely walking (10+ minutes in duration)

25. __ Needlework: knitting, sewing, needlepoint, etc.

26. ___ Dancing (mod/fast): line, ballroom, tap, square, etc.

27. ___ Bowling, boccie

28. Golf (walking to each hole only)

29. ___ Racquet sports: tennis, racquetball

30. ___ Billiards

31. __ Other: 


\section{YALE PART 2}

Now I would like to ask about certain types of activities that you have done during the past month. I will ask you about how much vigorous activity, leisurely walking, sitting. standing. and other things that you usually do.

32. About how many times during the month did you participate in vigorous activities that lasted at least 10 minutes and caused large increases in breathing, heart rate, or leg fatigue or caused you to sweat?

\begin{tabular}{|c|c|c|c|c|}
\hline $\begin{array}{c}\text { Not at all } \\
\text { (go to Q34) }\end{array}$ & $\begin{array}{c}\text { 1-3 Times } \\
\text { Per Month }\end{array}$ & $\begin{array}{c}1-2 \text { Times } \\
\text { Per Week }\end{array}$ & $\begin{array}{c}3-4 \text { Times } \\
\text { Per Week }\end{array}$ & $\begin{array}{c}5 \text { or more Times } \\
\text { Per Week }\end{array}$ \\
\hline
\end{tabular}

33. About how long do you do this vigorous activity each time?

\begin{tabular}{|c|c|c|c|}
\hline $\begin{array}{c}\text { Not } \\
\text { applicable }\end{array}$ & $\begin{array}{c}10-30 \\
\text { minutes }\end{array}$ & $\begin{array}{c}31-60 \\
\text { minutes }\end{array}$ & $\begin{array}{c}60 \text { or more } \\
\text { minutes }\end{array}$ \\
\hline
\end{tabular}

34. Think about the walks you have taken during the past month. About how many times per month did you walk for at least 10 minutes or more without stopping which was not strenuous enough to cause large increases in breathing, heart rate, or leg fatigue or cause you to sweat?

\begin{tabular}{|c|c|c|c|c|}
\hline $\begin{array}{c}\text { Not at all } \\
\text { (go to Q36) }\end{array}$ & $\begin{array}{c}\text { 1-3 Times } \\
\text { Per Month }\end{array}$ & $\begin{array}{c}\text { 1-2 Times } \\
\text { Per Week }\end{array}$ & $\begin{array}{c}\text { 3-4 Times } \\
\text { Per Week }\end{array}$ & $\begin{array}{c}5 \text { or more Times } \\
\text { Per Week }\end{array}$ \\
\hline
\end{tabular}

35. When you did this walking, for how many minutes did you do it?

\begin{tabular}{|c|c|c|c|}
\hline $\begin{array}{c}\text { Not } \\
\text { applicable }\end{array}$ & $\begin{array}{c}10-30 \\
\text { minutes }\end{array}$ & $\begin{array}{c}31-60 \\
\text { minutes }\end{array}$ & $\begin{array}{c}60 \text { or more } \\
\text { minutes }\end{array}$ \\
\hline
\end{tabular}

36. About how many hours a day do you spend moving around on your feet while doing things? Please report only the time that you are actually moving.

\begin{tabular}{|c|c|c|c|c|c|}
\hline $\begin{array}{c}\text { Not at } \\
\text { all }\end{array}$ & $\begin{array}{c}\text { Less than } \\
1 \text { hr per } \\
\text { day }\end{array}$ & $\begin{array}{c}1 \text { to less } \\
\text { than } 3 \text { hrs } \\
\text { per day }\end{array}$ & $\begin{array}{c}3 \text { to less } \\
\text { than } 5 \text { hrs } \\
\text { per day }\end{array}$ & $\begin{array}{c}5 \text { to less than } \\
7 \text { hrs per day }\end{array}$ & $\begin{array}{c}7+\text { hrs } \\
\text { per day }\end{array}$ \\
\hline
\end{tabular}

37. Think about how much time you spend standing or moving around on your feet on an average day during the past month. About how many hours per day do you stand?

\begin{tabular}{|c|c|c|c|c|c|}
\hline $\begin{array}{c}\text { Not at } \\
\text { all }\end{array}$ & $\begin{array}{c}\text { Less than } \\
1 \text { hr per } \\
\text { day }\end{array}$ & $\begin{array}{c}1 \text { to less } \\
\text { than } 3 \text { hrs } \\
\text { per day }\end{array}$ & $\begin{array}{c}3 \text { to less than } \\
5 \text { hrs per day }\end{array}$ & $\begin{array}{c}5 \text { to less } \\
\text { than } 7 \text { hrs } \\
\text { per day }\end{array}$ & $\begin{array}{c}7+\text { hrs } \\
\text { per day }\end{array}$ \\
\hline
\end{tabular}


38. About how many hours did you spend sitting on an average day during the past month?

\begin{tabular}{|c|c|c|c|c|}
\hline $\begin{array}{c}\text { Not at } \\
\text { all }\end{array}$ & Less than 3 hrs & $\begin{array}{c}3 \text { hrs to less } \\
\text { than } 6 \text { hrs }\end{array}$ & $\begin{array}{c}6 \text { hrs to less } \\
\text { than } 8 \text { hrs }\end{array}$ & $8+$ hrs \\
\hline
\end{tabular}

39. About how many flights of stairs do you climb up each day? (Let 10 steps $=1$ flight)

40. Please compare the amount of physical activity that you do during other seasons of the year with the amount of activity you just reported for a typical week in the past month. For example, in the summer, do you do more or less activity than what you reported doing in the past month? (Interviewer - mark the right category for each season)

$\begin{array}{llcccc} & \begin{array}{l}\text { Lot } \\ \text { more }\end{array} & \begin{array}{l}\text { Little } \\ \text { more }\end{array} & \text { Same } & \begin{array}{c}\text { Little } \\ \text { less }\end{array} & \begin{array}{c}\text { Lot } \\ \text { less }\end{array} \\ \text { Spring } & 1.3 & 1.15 & 0 & .85 & .7 \\ \text { Summer } & 1.3 & 1.15 & 0 & .85 & .7 \\ \text { Fill } & 1.3 & 1.15 & 0 & .85 & .7 \\ \text { Winter } & 1.3 & 1.15 & 0 & .85 & .7\end{array}$




\section{Appendix G. Dietary Screening Tool}

DIRECTIONS: Please check one response to each question that best describes how you eat.

How often do you usually eat fruit as a snack?

Never

Less than once a week

1 or 2 times a week

3 or more times a week

How often do you usually eat whole grain breads?

Never or less than once a week

1 or 2 times a week

3 or more times a week

How often do you usually eat whole grain cereals?

Never or less than once a week

1 or 2 times a week

3 or more times a week

How often do you usually eat candy or chocolate?

Never

Less than once a week

1 or 2 times a week

3 or more times a week

How often do you eat crackers, pretzels, chips, or popcorn?

Never

Less than once a week

1 or 2 times a week

3 or more times a week

\section{How often do you eat cakes or pies?}

Never

Less than once a week

1 or 2 times a week

3 or more times a week 


\section{How often do you eat cookies?}

Never

Less than once a week

1 or 2 times a week

3 or more times a week

\section{How often do you eat ice cream?}

Never

Less than once a week

1 or 2 times a week

3 or more times a week

How often do you eat cold cuts, hot dogs, lunchmeats or deli meats?

Never or less than once a week

1 or 2 times a week

3 or more times a week

How often do you eat bacon or sausage?

Never or less than once a week

1 or 2 times a week

3 or more times a week

How often do you eat carrots, sweet potatoes, broccoli, or spinach?

Never

Less than once a week

1 or 2 times a week

3 or more times a week

How often do you eat fruit (not including juice)? Please include fresh, canned or frozen fruit.

Never or Less than once a week

1 or 2 times a week

3 to 5 times a week

Every day or almost every day

How often do you eat hot or cold breakfast cereal?

Never

Less than once a week

1 or 2 times a week

3 to 5 times a week

Every day or almost every day 
How often do you drink some kind of juice at breakfast?

Never or Less than once a week

1 or 2 times a week

3 to 5 times a week

Every day or almost every day

How often do you eat chicken or turkey?

Never or less than once a week

1 or 2 times a week

More than 3 times a week

How often do you drink a glass of milk?

Never or Less than once a week

1 or 2 times a week

3 to 5 times a week

Every day or almost every day

More than once every day

Do you usually add butter or margarine to foods like bread, rolls, or biscuits? Yes

No

Do you usually add fat (butter, margarine or oil) to potatoes and other vegetables?

Yes

No

Do you use gravy (when available) at meals?

Yes

No

Do you usually add sugar or honey to sweeten your coffee or tea?

Yes

No

Do you usually drink wine, beer or other alcoholic beverages?

Yes

No 
How often do you eat fish or seafood that IS NOT fried?

Never

Less than once a week

Once a week

More than once a week

How many servings of milk, cheese, or yogurt do you usually have each DAY? None

One

Two or more

How many different vegetable servings do you usually have at your main meal of the day?

None

One

Two

Three or more

Which of the following best describes your nutritional supplement use?

I don't use supplements

I use supplements other than vitamins and mineral

I use a multivitamin/mineral preparation (e.g. Centrum) 